\title{
Institutional complexity traps in policy integration processes: a long-term perspective on Swiss flood risk management
}

\author{
Thomas Bolognesi ${ }^{1}$ (D) . Florence Metz ${ }^{2}$ (D) Stéphane Nahrath ${ }^{3}$ (D)
}

Accepted: 9 October 2021 / Published online: 12 November 2021

(c) The Author(s) 2021

\begin{abstract}
Complexity is inherent to the policy processes and to more and more domains such as environment or social policy. Complexity produces unexpected and counterintuitive effects, in particular, the phenomenon of policy regimes falling short of expectations while made by refined policies. This paper addresses this phenomenon by investigating the process of policy integration and its nonlinearities in the long run. We consider that the increase in the number of policies unexpectedly impacts the policy coherence within a policy regime. We argue that, depending on the degree of policy interactions, this impact varies in direction and intensity over time, which explains nonlinearities in integration. The impact turns negative when the regime is made of numerous policies, which favors non-coordinated policy interactions. Finally, the negative impact prevents further integration as stated by the Institutional Complexity Trap hypothesis and explains the contemporary paradoxical phenomenon of ineffective policy regimes made of refined policies. Empirically, we draw on a relational analysis of policies in the Swiss flood risk policy regime from 1848 to 2017. We study the co-evolution of the number of policies and of their de facto interlinkages, i.e., the co-regulations of a common issue. Findings support that the Institutional Complexity Trap is a structural and long-term dynamic punctuated by periods of policy learning and policy selection. We identify three main phases in the evolution of the regime: the start (18481874), the development (1874-1991), and the Institutional Complexity Trap (since 1991).
\end{abstract}

Keywords Public policy $\cdot$ Integration $\cdot$ Coherence $\cdot$ Transaction costs $\cdot$ Polycentric governance $\cdot$ Water $\cdot$ Flood risk management

Thomas Bolognesi

thomas.bolognesi@unige.ch

Florence Metz

f.a.metz@utwente.nl

Stéphane Nahrath

stephane.nahrath@unil.ch

1 University of Geneva, Geneva, Switzerland

2 University of Twente, Enschede, The Netherlands

3 University of Lausanne, IDHEAP, Lausanne, Switzerland 


\section{Introduction}

Policy integration is a central and much promising approach to understand the functioning of polycentric governance systems. Policy integration explains how the different decision centers of a polycentric system, located at different institutional levels and in various policy sectors, interact and for what effects on the policy outcome. A common assumption is that policy integration leads to better policy outcomes (Jordan \& Lenschow, 2010; Lafferty \& Hovden, 2003; Tosun \& Lang, 2017). The success of this assumption may be due to its intuitive soundness, i.e., a better alignment between institutions, organizations, and policy objectives should induce better coordination and thus better outcomes. Since its first appearance in Underdal's study of marine policy (Underdal, 1980), scholarship on integration has been rather fragmented (Candel \& Biesbroek, 2016; Tosun \& Lang, 2017; Trein, Meyer, and Maggetti 2018). More recently, scholars have aimed to bridge this incohesive knowledge to pave the way for a unified understanding of the "what's" and "how's" of integration (Bolognesi \& Nahrath, 2020; Candel \& Biesbroek, 2016; Cejudo \& Michel, 2017; Metz et al., 2020; Trein et al. 2020). This paper intends to contribute to this momentum by analyzing the co-evolution of policy creation, policy coherence, and policy integration in the long run.

Many contemporary policy problems like health, migration, or climate change are boundary-spanning. In such cases, the polycentric nature of the governance is somehow exacerbated because of the many decision centers located at different levels and policy sectors (Carlisle \& Gruby, 2019; Ostrom, 2010). As a result, the identification of the current governance system (i.e., the relevant rules, actors and organizations) reveals more difficult (Jochim \& May, 2010; Varone et al., 2013). For instance, agricultural, water quality, and general public contract policies contribute together to the governance of drinking water delivery. Each policy is part of a policy regime (hereafter "regime" or "PR") defined as the combination of the multiple public policies that regulate the rivalries around goods and services related to a given shared resource, i.e., the policy problems. On the ground, these rivalries often reflect conflicts of interest between the use and the protection of resources among policy sectors. For the provision of drinking water, for example, policies adopted in the agricultural and water sectors reflect competing claims.

The integration of a regime reflects the combination of these policies and how they interact in a (non)complementary manner and with a comprehensive coverage of the policy problems (Cejudo \& Michel, 2017; Gerber et al., 2009). Consequently, we define integration as the combination of the extent and the coherence of a regime. The extent is the scope of the uses (as well as rivalries) regulated by the regime and is considered to positively affect integration. In the field, an increase in extent consists of adopting new policy instruments in legal documents like laws and ordinances (Howlett, 2009). The notion of coherence refers to the quality of public policies (e.g., clarity, feasibility) and their interactions (e.g., complementarity and explicit coordination of policy instruments and hierarchization of policy objectives) (Bolognesi \& Pflieger, 2019; Cejudo \& Michel, 2017; May et al., 2006; Varone \& Nahrath, 2014). A coherent regime means that the way policies consider actors (targets and beneficiaries), time, causal effects of instruments and their concrete setting is not contradictory, but complementary. Coherence favors the effectiveness of the policy instruments and has a positive impact on integration. In the field, an integrated regime regulates all existing uses (high extent) in a clear and self-reinforcing manner (high coherence) (Gerber et al., 2009). 
There are three primary intertwined benefits from policy integration identified in the literature. First of all, integration is expected to offer better fits or alignment between the policy design and the policy objectives (Anderies \& Janssen, 2013; Ingold et al., 2018; Renou \& Bolognesi, 2019; Teisman \& Edelenbos, 2011). A second significant benefit is the limitation of institutional interplays and the capacity to make different policy domains work in a complementary manner (Al-Saidi \& Elagib, 2017; Jordan \& Lenschow, 2010; Oberthür and Stokke 2011). This benefit is also referred to as the management of the negative externalities of polycentrism (Lubell, 2013; Lubell et al., 2017). The third expected benefit from policy integration is the reduction of the transaction costs associated with policy coordination. Integration should allow for a more efficient organization of political administrative processes and a reduction of transaction costs (Feiock, 2013; Feiock et al., 2017; Garrick et al., 2013; Mewhirter et al., 2018; Swann \& Kim, 2018; Yi et al., 2018).

Although considered an important issue by many, processes of policy integration mostly remain obtuse. Candel and Biesbroek (2016) stressed that studying "interdependencies and interactions in the context of policy integration is a crucial next step for integration research." Indeed, the very recent literature on the dynamics of integration provides a nuanced view of the positive effects of integration on policy coordination and outcomes (Biesbroek and Candel 2019; Bolognesi \& Nahrath, 2020; Candel, 2017). For instance, Candel (2017) identifies 1278 studies that have been published on policy integration, of which only 18 assess the effect of integration on policy outcomes. Among these studies, only two found this impact was substantially positive. Furthermore, Adam et al., (2018) emphasize how policy accumulation represents a challenge for both practitioners and scholars.

In this article, we address the challenge of understanding policy integration processes through the interaction between policy extent and coherence, empirically captured by policy interlinkages in the Swiss flood management since 1848. In so doing, the paper contributes to explain recent nuanced views on integration, disintegration process, and, more generally, to the understanding of the evolution of polycentric governance systems (Berardo \& Lubell, 2016; Carlisle \& Gruby, 2019; Thiel et al. 2019; Trein et al. 2020; Biesbroek \& Candel, 2019).

We contribute to the explanation of integration processes by arguing that integration follows a nonlinear pattern, because, at some point, extent increases are likely to reduce coherence. Expanding the regime's extent consists of implementing new policies that allow for regulating more uses and resolving more conflicts. As such, extent increase represents an instrumental leverage ability for integration. Most of the literature focusses on the extent by assuming that the regime's capacity to improve the sustainable use of a resource lies in its ability to address multiple users and usages. This literature stands on the underlying assumption that coherence remains constant as the extent expands. As such, previous studies tend to reduce policy integration to the extent of the PR (Cejudo \& Michel, 2017). Nonetheless, we argue there is a turning point from which coherence is not stable anymore because it is negatively affected by extent. Increasing the number of policies, i.e., the extent, expands room for incoherencies as policy issues are interdependent but policies are not necessarily coordinated (Bolognesi \& Nahrath, 2020; Biesbroek and Candel 2019; Oberthür and Stokke 2011). This negative side-effect of extent leads to an Institutional Complexity Trap (Bolognesi \& Nahrath, 2020). As a consequence, the impact of extent on integration is nonlinear over the years and these nonlinearities are critical for understanding integration patterns.

This paper aims to demonstrate how integration, in the long run, evolves as a function of the extent and coherence of the regime. We emphasize how the relation between extent 
and coherence is critical to understand the nonlinearities of policy integration, including their significant practical implications. Developing extent could reduce, under certain conditions, the regime's integration. Policies can affect integration positively when offering coordination mechanisms, but uncoordinated policy interlinkages reduce the overall coherence of the regime. Indeed unexpected policy interlinkages are associated with transaction costs (Bolognesi \& Nahrath, 2020; Bolognesi \& Pflieger, 2019), the sum of which creates a space for incoherencies and should limit integration. Furthermore, we assert that there is a tipping point from which this negative mechanism strengthens as extent increases, leading to the recently implemented Institutional Complexity Trap (ICT) model. We offer a reliable delineation of the evolution of extent and policy interlinkages by scrutinizing the Swiss flood policies from 1848 to 2016 in order to test the ICT model.

We present our theoretical proposition in the next section ("Theory: disentangling the long-term dynamics of policy integration" section), followed by the description of our empirical strategy and materials ("Method and materials" section). In "Results" section, we detail our results. The implications and limits of our theoretical proposition are discussed in the last section of the paper (Sect. Discussion and conclusion).

\section{Theory: disentangling the long-term dynamics of policy integration}

\section{Evolution of integration}

Policies are typically organized in separate sectors, such as health, economics, or environmental protection. Each of those policy sectors is specialized in regulating a set of issues, i.e., societal problems addressed by means of political solutions (Metz et al., 2020). The fragmented structure of governments or legal documents (e.g., health law and environmental law) reflects the specialization of policy sectors in a set of specific issues. On the one hand, such specialized policy sectors constitute pillars, which create order with clear competences, procedures, and specialized know-how (Peters, 2015). On the other hand, however, they constitute "policy silos," which neglect that policy issues cut across sectors, and, thereby can facilitate policy failure (Howlett \& Ramesh, 2014).

Policy issues often are not sector-specific, but they establish interdependencies across policy sectors. Interdependence here means that causes or effects of issues and political solutions in one policy sector impact issues and political solutions in other policy sectors (Aoki, 2007; Bolognesi \& Nahrath, 2020; Mewhirter et al., 2018). For example, the environmental and health sectors are interdependent as air or water quality issues can impact human health. As a consequence, policy effectiveness in one policy sector depends on and affects performance in other policy sectors (Pham-Truffert et al., 2020).

In order to understand such policy interdependencies across policy sectors, scholars have coined the notion of policy integration (Jordan \& Lenschow, 2010; Lafferty \& Hovden, 2003; Nilsson \& Persson, 2003). The promise of policy integration is to create situations in which different social, economic, and environmental policy sectors mutually reinforce each other's goals, thereby fostering synergies and ultimately promoting sustainable development (Dupont \& Jordan, 2021; Gerber et al., 2009; Tosun \& Lang, 2017).

While scholars have written about integration in terms of coordinating policies across sectors and levels (Lubell, Robins, and Wang 2014; Bolognesi \& Pflieger, 2019; Poteete, 2012), recent scholarship has drawn attention to the temporal dimension of policy integration. Metz and Glaus (2019) or Bolognesi Nahrath (2020) highlight that policy integration 
Fig. 1 Types of policy regime according to extent and coherence (from Gerber et al., 2009)

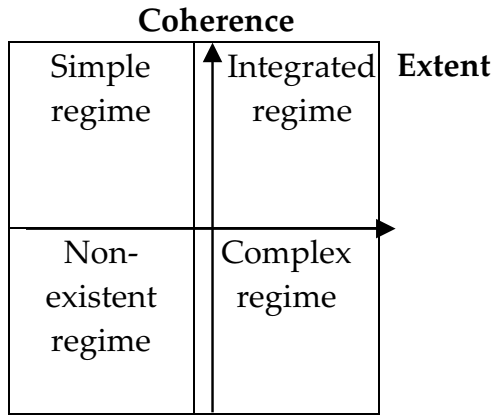

also concerns coordinating policies across time into a coherent policy regime. The role of time to understand policy effectiveness or design criteria remains under-investigated but critical because policy mixes could create counterproductive effects or synergies when evolving (Cejudo \& Michel, 2021; Howlett, 2019). One policy instrument may appear "anachronic later" (Cejudo \& Michel, 2021, p.2) because not coordinated or incoherent with the more recent policy instruments. Howlett (2019) emphasizes that considering the temporal dimensions in policymaking highlights potential contradictions in policy mixes, especially when policy interactions are unintentional. Procedural measures enabling coordination of policies over time are needed to avoid potential contradictions and favor policy integration (Cejudo \& Michel, 2021; Howlett, 2019).

With policy regime, we mean the entirety of policies, i.e., legislations and regulations, pertaining to a specific policy issue. Bolognesi and Nahrath (2020) propose a theoretical model for understanding the integration process in the long run (>100 years) ("Appendix 1"). They build on the Institutional Resource Regime (IRR) by Gerber et al., (2009), which defines two dimensions to classify regimes: extent (the total number of regulated issues at a given time) and coherence (the degree of coordination and complementarity between the different sets of rules regulating issues). Extent and coherence co-evolve such that the number of regulated issues increases through the adoption of new policies over time. With a growing number of policies, the extent of the regime increases. A larger regime is also more complex and less coherent unless efforts are made to coordinate the multiple regulations.

By combining the dimensions of extent and coherence, four policy regime types can be differentiated (Fig. 1):

(1) A non-existent regime (low extent, low coherence) exists when a sector's issues are not (yet) regulated (bottom left in Fig. 1).

(2) A simple regime (low extent, high coherence) develops once a limited number of noninterdependent issues are regulated in a coherent way (top left).

(3) A complex regime (high extent, low coherence) refers to a situation where many regulations have been added and incoherencies materialize (bottom right).

(4) An integrated regime (high extent, high coherence) describes an ideal state where policy issues across sectors are regulated in a coherent way (top right).

To date, the processes of integration are under-investigated (Candel \& Biesbroek, 2016; Trein et al. 2020b), i.e., why and how regimes move from one stage to the other-or fail to do so. We further specify the processes happening during the third stage, i.e., during a 


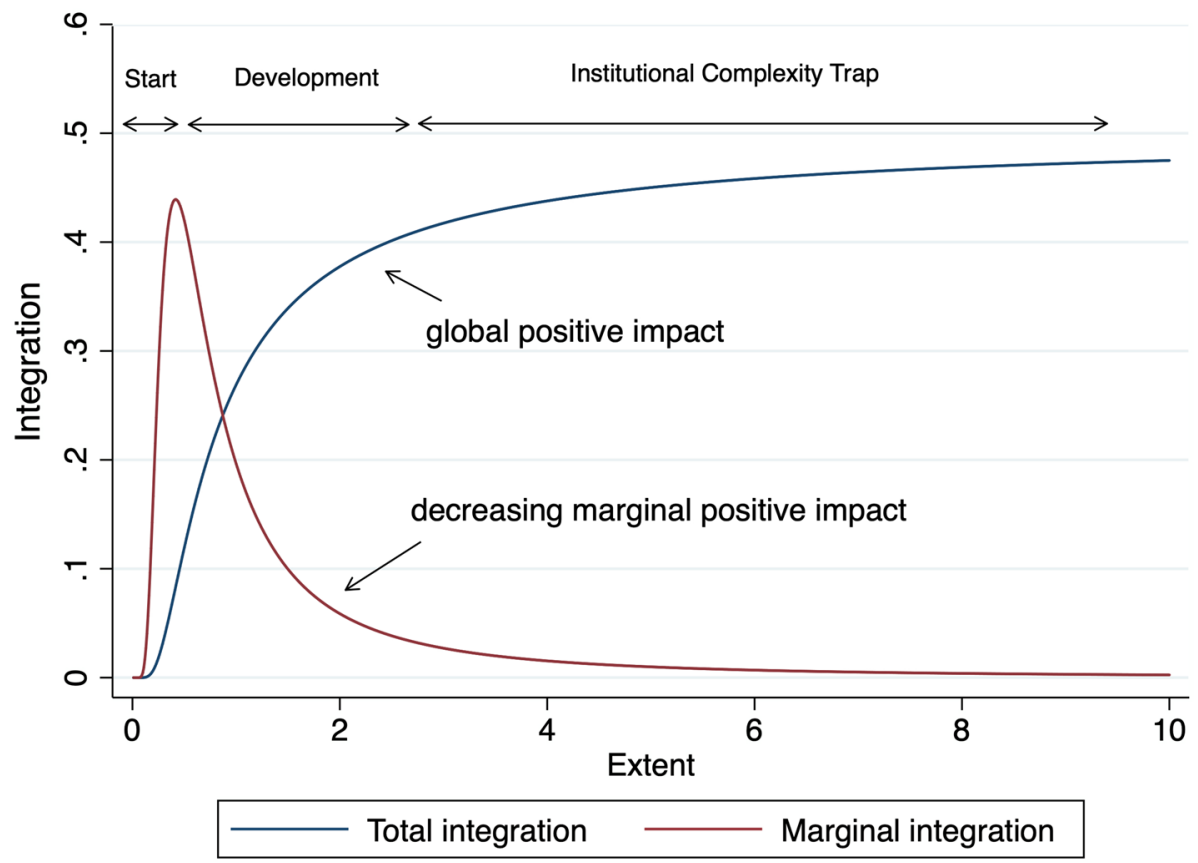

Fig. 2 Evolution of integration as a function of extent of the policy regime, according to the ICT hypothesis (Bolognesi \& Nahrath, 2020). We distinguish the total (blue line) from the marginal positive (red line) effect of extent on integration. The marginal effect is the assumed effect of each new regulation on integration. The three phases are marked by tipping points, i.e., changes in derivatives

complex PR. Following Bolognesi and Nahrath (2020), we argue that PR often become trapped in complexity during stage three and, therefore, do not attain the final stage of an integrated PR. Instead, policies remain poorly coordinated across sectors, thereby lacking coherence and leaving space for contradicting goals or negative spillover effects.

\section{Institutional complexity traps}

An institutional complexity trap unfolds in three phases: a start, a development, and an institutional complexity trap (Fig. 2). The first phase precedes the actual process and is characterized by a simple regime with a slow increase in adopted policies (extent).

The second phase denotes the development of the regime, and is comprised of several steps, hereafter denoted as steps $2 \mathrm{a}$ and $2 \mathrm{~b}$. In the first instance (2a), the regime grows (extent), while remaining coherent. Coherence remains, for example, when each sector regulates its "own" separate issues and issues do not exhibit much interdependencies. In the second instance ( $2 \mathrm{~b})$, the regime's extent continues to grow with the adoption of additional policies. As a result of the growing extent, a tipping point is reached where more and more interdependencies between regulated issues materialize, leading to incoherencies between the adopted policies.

At its core, the ICT model states that extent and coherence are nonlinearly connected. More precisely, the expansion of the extent has two different and opposite effects on coherence. During step 2a, more uses are regulated, and thus the regime becomes more 
differentiated, or in other words, wholistic. Here, extent relates positively to the integration of the regime. As more and more issues are being regulated during step $2 b$, however, interdependencies between issues become apparent. New policies are very likely to also affect issues already regulated in other sectors. Consequently, coordination between the different regulations becomes vital, but also more difficult to oversee and thus time-consuming. Transaction costs of policy coordination rise (Feiock, 2013; Kim et al., 2020). The increase in extent creates a decreasing marginal positive impact on the integration of the regime as illustrated by the red line in Fig. 1. The expansion of the extent can impair coherence, which in turn will have an indirect negative impact on integration of the policy regime.

Additionally, the central hypothesis of the ICT model is that the indirect negative effect (2b) prevails in the long run, thereby dominating over the direct positive impact (2a). This tipping point marks the entering into the third phase, the Institutional Complexity Trap. The complex regime regulates various interdependent issues. Each additional policy impacts not only one sector, but a multitude of other sectors due to multiple interdependencies between issues across sectors. In other words, the marginal positive impact that extent had on coherence in previous stages tends to be null during an ICT. Instead of moving to an integrated state, the overall regime remains complex. Policies from different sectors can conflict or even cancel each other out, thereby limiting policy effectiveness or feasibility.

Based on these processes, we formulate two complementary hypotheses:

Hypothesis 1 (H1) The evolution of policy interdependencies follows a different pattern than the growth of the number of public policies.

Hypothesis $2(\mathrm{H} 2)$ There is a tipping point from which the number of public policies is growing less rapidly than the number of issue interdependencies. This tipping point marks the entrance into an ICT, where extent affects coherence negatively.

Our hypotheses complement other explanations of coordination failures focusing on cognitive limitations, implementation issues, politics (Adam et al., 2019a, 2019b), and conflicts among actors (Hustedt \& Danken, 2017).

\section{Coherence cycles and institutional complexity trap}

We have argued that policy regimes follow the trajectory of an ICT when considering time horizons of 100 years or more. The ICT captures a structural aspect of the regime. A focus on shorter phases of time highlights mechanisms of policy changes, such as adaptation and learning, which are more dynamic and less structural. Long-term, structural ICT processes interact with dynamic mechanisms that are visible on shorter timescales. Understanding this interaction is important as adaptation and learning are likely to improve regime coherence and could possibly solve the ICT problem. We thus consider coherence cycles defined as shorter phases where policy improvements occasionally contribute to the regime's coherence.

More specifically, there are competing mechanisms at work in the long- and shortterm. In the long-term, policies tend to be rather resistant to change, i.e., they remain stable (Mahoney \& Thelen, 2009; Peters, 2015; Roland, 2004). As a result, policy regimes grow in extent each time a new policy is added, which provides room for incoherencies between different policies composing the regime. In the short-term, by contrast, competing mechanisms are at work. When attention to a policy issue spikes (Baumgartner et al., 2009; 
Capano \& Galanti, 2018; Capano \& Lippi, 2017), not only new policies are added, but existing policies can also be adapted in order to improve policy coherence. Such improvement can take three forms: adaptation (an existing policy is amended), replacement (an existing policy is replaced by another one) or termination (an existing policy is abolished). In all three cases, policy change occurs while the regime does not grow in extent. Consequently, coherence should improve together with the overall integration of the policy regime.

The mechanisms that drive such improvements involve, among others, learning, which should ideally lead to the survival of the most effective, or 'fittest' policies. Policy learning takes the form of a trial-and-error process; it allows for crafting policies and refining their design toward a more desirable outcome according to actors (Ostrom, 2005). Additionally, a Darwinist competition can arise between policies and policy instruments where actors select and substitute policies in favor of the most efficient ones (Hodgson \& Knudsen, 2010; Williamson, 1985).

When a window of opportunity opens for policy change, the mechanisms of learning and Darwinist competition can contribute to improving coordination between different policies composing the regime. These coherence cycles are both embedded in and counterbalance the ICT dynamics; we nevertheless argue that they do not change the structural trajectory of the PR. Despite occasional improvements, the multiplication of issue interdependencies substantially increases the need to coordinate the various components of the regime. As coordinating regime's components constitutes a task of growing difficulty, the regime continues to move toward an ICT in the long-term. We hypothesize:

Hypothesis $3(\mathrm{H} 3)$ In the short-term, policy adaptation, replacement, or termination contributes to improving the coherence of the policy regime. These adjustments are too limited to turn over a general and structural trend toward an ICT in the long-term.

\section{Method and materials}

\section{Flood protection in Switzerland}

We illustrate our argument by focusing on flood risk management in Switzerland. Policy integration is particularly relevant in flood risk management as strong spatial and sectoral interdependencies exist. For example, creating floodwalls in one location can severely impact flood pressures in other locations (Metz et al., 2020). Likewise, policy action in the insurance sector can influence risk behavior in the building sector. As a consequence of these interdependencies, policy integration is crucial for resilience against flood risks.

Switzerland has a long history of floods and flood risk management policies due to its alpine location, precipitation patterns, and geomorphology. Flood approaches initially focused on technical, infrastructure solutions. More recently, however, flood management has developed toward a regional planning approach with the aim to revitalize water (i.e., enlarging the river bed and floodplains) (Metz \& Glaus, 2019. Similar changes in approach transpired in the US and the Netherlands (Bergsma, 2018). ${ }^{1}$ Over time, the legal framework

\footnotetext{
1 More generally, there is no peculiarities in the Swiss policy decision-making system that disproportionally affects the likelihood of an institutional complexity trap. The Swiss political system does not contain more barriers to cross-sectoral coordination than other Western democracies (Fischer and Sciarini 2016; Kriesi and Trechsel 2008; Lijphart 2012; Trein and Maggetti 2020a) and the water regulatory regime is comparable to other European countries (Bolognesi 2018; Kissling-Näf and Kuks 2004; Lorrain 2005).
} 
grew and involved more and more policy sectors, e.g., emergency planning, environmental protection, insurances, or spatial planning. As a result, specialized laws (e.g., regional planning law, insurance law) have been adopted to regulate specific issues. Those issues, in turn, are interdependent. In order to take those interdependencies into account and prevent policy silos, the Swiss legislators created some linkages between laws, mostly through cross-references, in order to create a coherent legal framework.

Legislators created some coherences by linking laws to one another such that implementers do not only consider one approach, but instead adopt an integrated approach. For example, the Swiss Hydraulic Engineering Act (SR 721.100, Art. 3) stipulates that flood risk management is first and foremost a matter of maintenance and spatial planning. Only if those approaches are insufficient should built-infrastructure solutions be taken. This legal article encourages implementers to consider several approaches (maintenance, spatial planning, and engineering) when managing floods, thereby promoting cross-sectoral policy integration. Beyond this example, the Swiss legislators created linkages between some flood-relevant laws with the intention to promote coherence, but which also resulted in a rather complex legal framework. What is more, numerous interdependencies between flood issues are difficult to anticipate and only materialize later in the implementation process. Hence, issue interdependencies may not be matched by policy interlinkages.

In order to systematically analyze how the Swiss legal framework evolved over time, we draw upon two datasets. First, we utilize an inventory of 169 years of Swiss laws relevant to flood risk management, i.e., all laws since the foundation of the Confederation in 1848 (Metz \& Glaus, 2019). This dataset serves to analyze extent, i.e., the number of policies adopted over time. Secondly, we employ a dataset for the issue interdependencies that exist between flood-relevant laws.

\section{Observing changes in policy extent}

To observe the extent of the Swiss flood policy regime over time, we compiled a policy inventory by counting and classifying flood-related policy instruments that have been adopted at a national level in Switzerland between 1848 and 2017 (Metz \& Glaus, 2019). We define policy instruments as single means that were introduced to manage the risk of flooding in Switzerland. Examples of policy instruments in flood risk management include bans on deforestation, legal requirements regarding protective flood constructions, land-use plans, hazard maps, or water body maintenance measures. Each policy instrument is laid down in a policy document, i.e., in public laws and ordinances, whereby a policy document can contain several instruments.

We compiled this inventory of Swiss flood policies by directly analyzing the content of Swiss legislation (“Appendix 2"). To identify relevant laws and instruments, we drew upon government websites ${ }^{2}$ and reports (FOEN, 2013; FOWG, 2001, 2002) or academic research (Schnitter, 1992; Zaugg, 2006). We thereby identified a total of 29 laws and ordinances, and 89 relevant policy instruments, respectively. Our dataset also includes additional variables such as the type of instrument that was adopted, the year of its adoption and dismantlement, as well as the type of approach with which it was associated.

Focusing on policy instruments enables us to provide a fine-grained understanding of the extent of the Swiss flood regime. Our dataset records the year of adoption, amendment,

${ }^{2}$ Legal texts are available online at www.admin.ch or at www.lexfind.ch. 
or abolishment of a specific policy instrument. The unit of analysis here are single policy instruments, which capture policy change (adoption, amendments, abolishment) more granularly than if we had used the legal document (law or ordinance) as the unit of analysis. We record precise dates by tracking the amendments over time of the relevant articles within legal texts through a detailed version analysis. Out of the 89 instruments that were introduced, 27 have since been abolished.

\section{Observing changes in policy coherence}

In order to differentiate policy extent from coherence, we draw upon a second dataset targeted at observing the coherence of the Swiss flood policy regime over time. This dataset has been gathered independently from the first one on extent. To capture extent as explained previously, we coded the adoption of policy instruments in laws. To capture coherence, by contrast, we coded the regulation of policy issues in laws. As such, we account for the coregulation of issues by different laws (or ordinances). We consider these co-regulations as issue-based policy (inter)linkages.

More concretely, interdependencies in the Swiss flood regime capture the degree to which legal documents (laws and ordinances) co-regulate flood-related issues. Issues refer to flood risk-related collective action problems addressed by means of political solutions (Metz \& Glaus, 2019; Metz et al., 2020). For example, flood risk maps represent an "issue." Such maps refer to areas where there is a high risk of flooding and serve as a spatial planning tool to avoid constructions in flood-prone areas. The need to adopt flood risk maps arose on the political agenda in Switzerland as a flood-related issue, which was then regulated through the passing of multiple acts specifying who, when, and how flood risk maps had to be adopted. Those acts co-regulate the issue of flood risk maps. Interdependencies exist since numerous legal documents co-regulate the issue of flood risk maps. Ideally, the various legal documents are perfectly coordinated with each other, thereby creating a coherent legal framework. Practically, however, not all legal acts are necessarily coordinated, especially when acts belong to multiple governance sectors and levels. In our language, issues are 'interdependent' and policies are 'interlinked' if they co-regulate interdependent issues.

First, we identified 11 issues related to flood risk management (Table 1) from a complete list of a total of 56 policy issues covering all aspects of Swiss water governance (Angst, 2018). The 56 issues stem from a research project on Swiss water governance, in which a complete set of water-relevant issues was gathered through a bottom-up procedure based on a thorough document analysis (for a detailed description of documents chosen and coding procedure see Metz et al., 2020 and Brandenberger et al., 2020). From this large set of issues pertaining to Swiss water governance, we singled out those 11 issues specifically related to Swiss flood risk management (see Table 1).

Secondly, we assessed where those 11 issues are regulated in the 29 laws and ordinances that we inventoried in the dataset capturing policy extent. We systematically went through each article of the laws and ordinances and manually coded whenever one or more of the listed 11 flood-related issues was regulated. The resulting dataset specifies whether an issue is regulated in a specific article of a law (or ordinance) and, conversely, which laws co-regulate one or several issues. Figure 3 depicts our approach in a graphical manner, indicating that we operationalized issue-based policy interlinkages by coding the co-regulation of one (or several) issue(s) by a pair of laws (left in Fig. 2). We then projected this bipartite issue-law matrix onto a unipartite, weighted law-law matrix (right in Fig. 2), which records the interlinkages between laws as the number of 
Table 1 Flood-related issues included in the study

\begin{tabular}{|c|c|}
\hline Issue & Definition \\
\hline Habitat loss & $\begin{array}{l}\text { The loss or degradation of aquatic habitats that can occur following } \\
\text { the building of flood prevention constructions such as dams }\end{array}$ \\
\hline Delimitation of watercourse corridors & $\begin{array}{l}\text { Watercourse corridors (Gewässerraum) is a legal concept referring } \\
\text { to the boundary that is designated around a waterbody in order to } \\
\text { protect it from, e.g., degradation due to construction activities }\end{array}$ \\
\hline Hydropower operation impacts & $\begin{array}{l}\text { The operation of hydropower facilities has implications for the } \\
\text { floodwater prevention (as is the case, for example, with the reten- } \\
\text { tion capacities of hydropower dams) }\end{array}$ \\
\hline Revitalization & $\begin{array}{l}\text { Revitalization measures (the restoration of rivers to what is per- } \\
\text { ceived to be a more natural state) can increase the rivers' retention } \\
\text { capacities, but they can also conflict with technical protection } \\
\text { measures }\end{array}$ \\
\hline Biotope conservation & Refers to the conservation of biotopes for, e.g., amphibians \\
\hline Dam safety & Ensuring the safety of large dams constructed for hydropower \\
\hline Drainage planning & Refers to municipal water management \\
\hline Flood risk maps & Refers to both the creation and update of flood risk maps \\
\hline Lake regulation & $\begin{array}{l}\text { The regulation of Swiss lakes' water levels plays an important role } \\
\text { in mitigating the impacts of floods, but faces trade-offs regarding } \\
\text { the impacts that changes in lake levels have on ecosystems and } \\
\text { shipping activities }\end{array}$ \\
\hline Flood protection concept & $\begin{array}{l}\text { Overall, more general plans and strategies regarding flood protec- } \\
\text { tion }\end{array}$ \\
\hline Technical flood protection & $\begin{array}{l}\text { Implementation and maintenance of technical means such as dams } \\
\text { or sediment traps }\end{array}$ \\
\hline
\end{tabular}

Fig. 3 Operationalization of issue-based policy interlinkages ( adapted from Metz et al., 2020). Left graph: Laws (circles) co-regulating (ties) issues (triangles); right graph: laws (circles) are interdependent over co-regulated issues (ties)
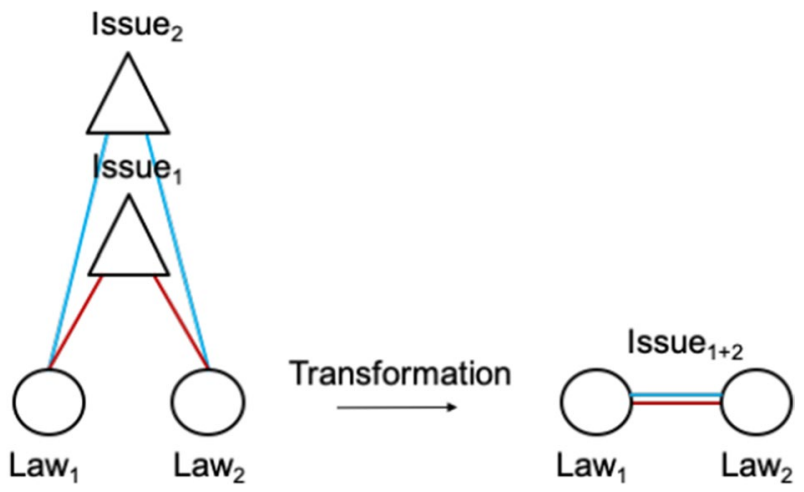

co-regulated issues between any pair of laws. This matrix can be displayed as a network, whereby the ties between laws correspond to the number of co-regulated issues.

Co-regulations establish interlinkages between legal documents by capturing issue interdependencies between legal documents and by acting as a proxy for the regime's (in) coherence. The more interlinkages that exist, the more coordination between legal documents would be necessary to create a coherent regime. Without such coordination, incoherence is likely to materialize through conflicting goals during policy implementation. 
Fig. 4 Evolution of issue-based policy interlinkages when adding one law. With one added law $\left(\operatorname{law}_{3}\right)$, the number of interlinkages increases from two to four compared to Fig. 2 (right graph)
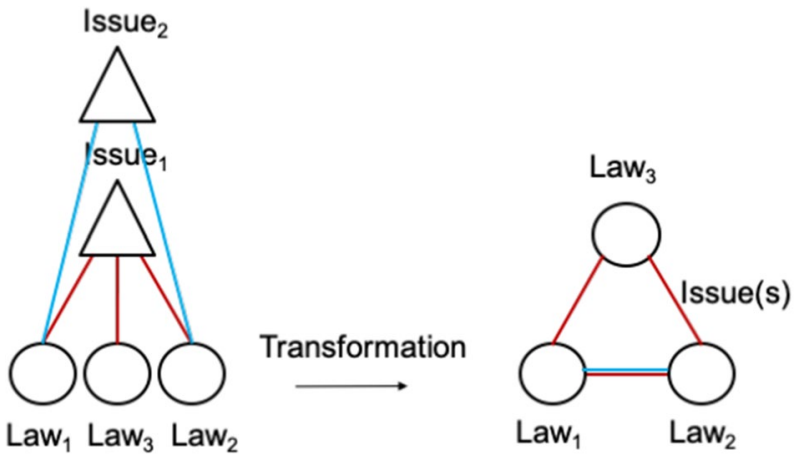

In the third step, we analyze how the co-regulation of issues evolved over time by counting the number of interdependencies (ties) between laws at different points in time (Fig. 4). Our dataset includes information on when an issue was first mentioned in a law. Where the flood-related issue was mentioned after the introduction of the law - for instance, in 2010 when the law had been adopted in 2000 — we have taken the date of that mention (2010) as the reference point. We then analyze the evolution of the interdependencies over time by aggregating three periods (1848-1990, 1990-2000, 2000-2017).

\section{Comparing changes in extent and coherence}

We compare the evolution of policy extent and coherence over time. We operationalize extent by counting the number of policy instruments regulating floods in legal documents over time. We operationalize incoherencies by counting the flood-related interlinkages between legal documents over time, i.e., the more interlinkages are present, the more incoherencies are likely. Policy actors are likely to adapt the regime to improve its coherence. These adaptations consist of modifying, replacing, or abrogating policy instruments. We use the share of abolished policy instruments to identify this specific change in coherence.

For hypothesis testing and comparability, Bolognesi and Nahrath (2020) formalized a simple model of the Institutional Complexity Trap. Because of the three steps of regime evolution toward an ICT, they argue that integration follows a sigmoidal function of extent. Graphically, integration should draw an S-shaped curve over time. Like in Fig. 2, we extrapolate integration from our extent data using: $I_{i, j}=\frac{1}{1+\exp ^{1 / r}}$ with $I_{i, j}$ referring to the level of integration $I$ of the regime $i$ regulating the resource $j$ with the regulatory instruments $r$ (i.e., extent). This extrapolation enables us to date integration patterns and phases in time.

\section{Results}

\section{Evolution of extent}

Figure 5 portrays the evolution of the extent of the Swiss flood regime between 1848 and 2017. Initially, flood risk management focused on infrastructure-based approaches (green). In the 1870 s, floods were attributed to forest clearances. As a consequence, reforestation was mandated in article 24 of the Federal Constitution on forest conservation in 1874. 


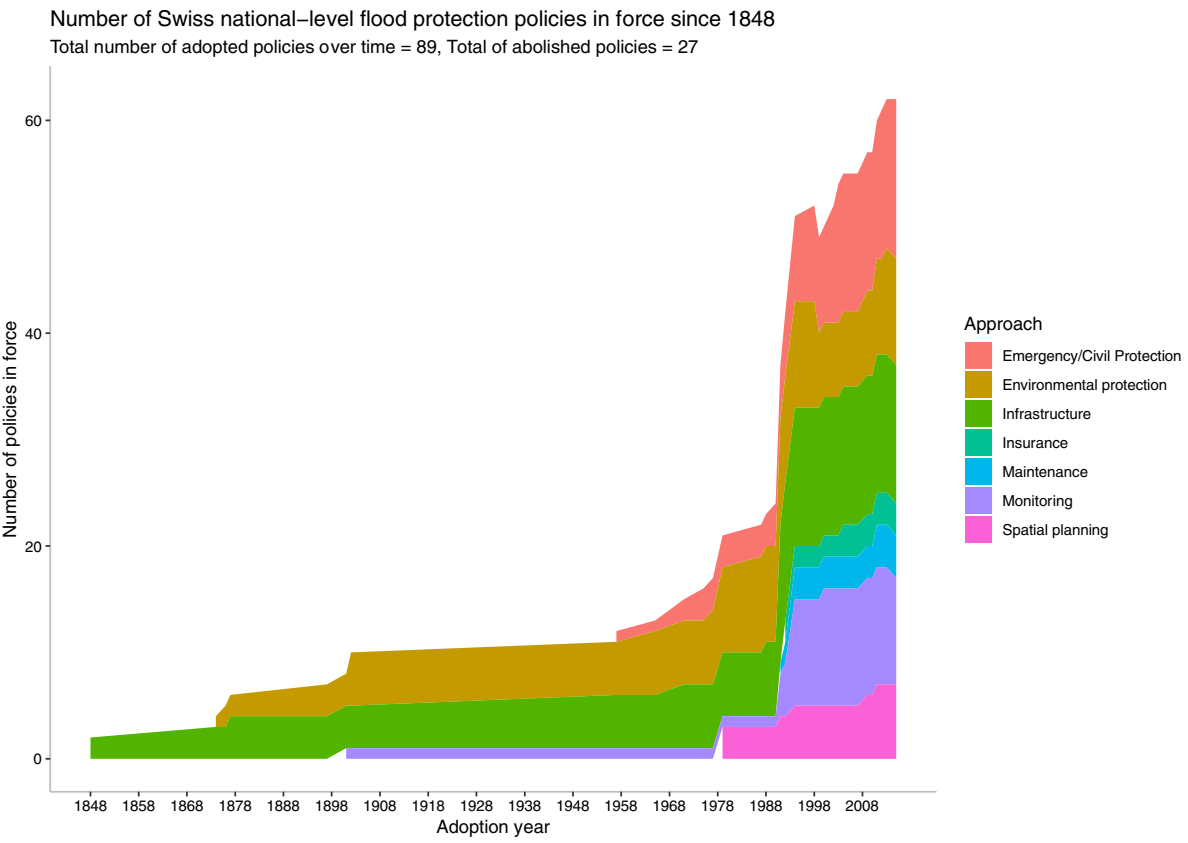

Fig. 5 Evolution of the policy regime's extent in Swiss flood risk management (1848-2017)

Moreover, protective forests were introduced together with clearing bans in 1876. Both instruments are classified under environmental protection (yellow). Monitoring instruments, e.g., of water levels, were introduced in the late nineteenth century, while instruments of emergency and civil protection were adopted in the 1950s. Beginning in the 1990 s, the number of instruments adopted by each policy approach grew exponentially, as instruments related to insurances and water body maintenance were also newly introduced. In sum, Fig. 5 illustrates that more and more policy instruments have been adopted in relation to flood risk management with an almost exponential growth, which is a sign of a policy specialization and, presumably, of a siloization of individual elements in the Swiss flood regime.

\section{Evolution of coherence: accelerating policy interlinkages}

To grasp the effect that extent has on coherence, we look at the way policy documents interrelate through co-regulating flood risk issues. We focus on 1990 as a starting point, because very few legal documents, and therefore interlinkages, existed prior to then (“Appendix 2" presents the detailed evolution of policy networks since 1848).

The nodes in Fig. 6 represent the laws through which flood-relevant issues have been regulated. The ties indicate policy interlinkages, i.e., when a pair of laws co-regulates the very same issue. The thickness of the ties is proportional to the number of the co-regulated issues. Figure 6 shows the evolution of the number of laws and their interlinkages over three decades, whereby gray ties refer to pre-exited ties in the previous phase (starting from 1990), and red ties refer to newly created ties (ties that appeared in the last decade). 


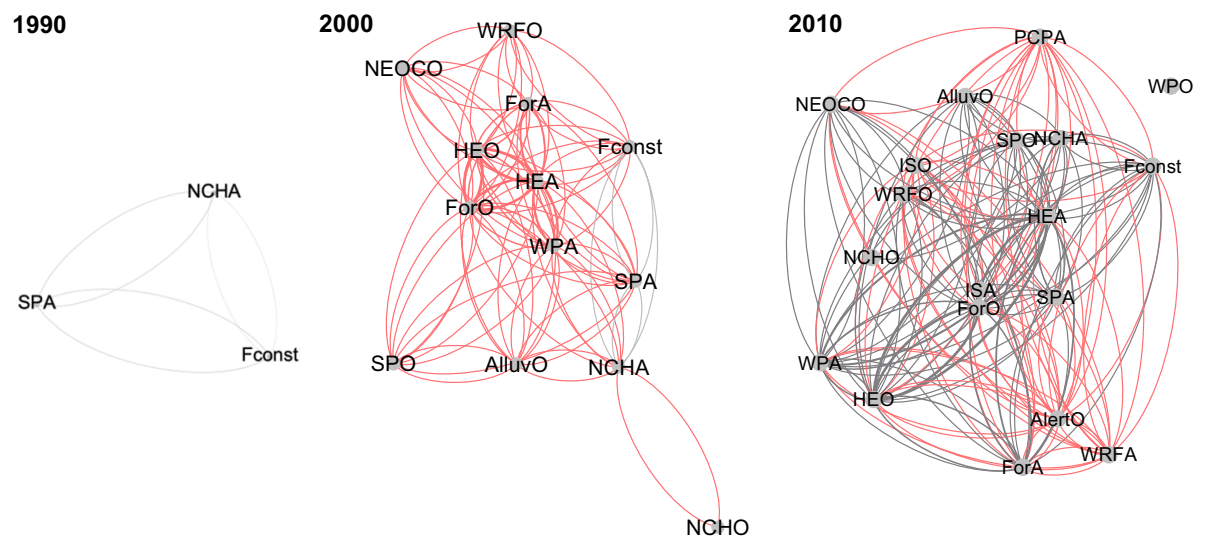

Fig. 6 Multiplication of interlinkages between policy from 1848 to 2017 in the Swiss flood regime. Note: gray edges = linkages already present in previous phase; red edges = new linkages created between 1990 and 2000 or 2000 and 2010. Legend: AlertO=Alerting- and Security Ordinance; AlluvO=Alluvial Areas Protection Ordinance; Fconst=Federal Constitution of the Swiss Confederation; ForA=Forest Act; ForO = Forest Ordinance; HEA = Hydraulic Engineering Act; HEO=Hydraulic Engineering Ordinance; ISA = Insurance Supervision Act; ISO=Insurance Supervision Ordinance; NCHA= Nature and Cultural Heritage Act; $\mathrm{NCHO}=$ Nature and Cultural Heritage Ordinance; NEOCO $=$ Ordinance of the National Emergency Operations Centre; PCPA = Population- and Civil Protection Act; SPA = Spatial Planning Act; $\mathrm{SPO}=$ Spatial Planning Ordinance; WPA =Waters Protection Act; WPO $=$ Water Protection Ordinance; $\mathrm{WRFA}=$ Water Retaining Facilities Act; $\mathrm{WRFO}=$ Water Retaining Facilities Ordinance

In 1990, we observe six ties between three legal acts (Fig. 5). The Federal Constitution was the only act in place to regulate flood protection in 1848. In 1979, the Spatial Planning Act (SPA) co-regulated flood-relevant issues together with the Federal Constitution. From 1987, flood-related issues also started to be co-regulated by the Nature and Cultural Heritage Act (NCHA), the Federal Constitution (Fconst), and the Spatial Planning Act (Fig. 4).

During the decade 1990-2000, the number of ties increased from 6 to 100. By 2010, the mix of inherited past (gray) and new (red) interlinkages between policies was more visible, highlighting the shift toward a potential institutional complexity trap when the number of red ties increased significantly. In 2010, the number of interlinkages continued to increase, reaching 174.

Over time, the number of issue-based interlinkages between laws increasingly grew and ties became stronger, which demonstrates that laws are increasingly co-regulating interdependent flood-related issues, but in an unexpected way. In 2020, there was no explicit coordination between the various policy instruments that were part of the 9 main legal texts constitutive of the Swiss flood policies ("Appendix 2"). In fact, a vast majority of laws and ordinances do not make any reference to one or the other legal text of the corpus even though they co-regulate interdependent issues. There is no reference to another law in 93\% of the 72 possible cross-references. Out of a total of 9 explicit situations of coordination between policy, i.e., policy cross-references, only 5 refer to flood protection, indicating that a vast majority of the interlinkages between policies are unexpected.

As such, the legal framework reflects that actors involved in the Swiss flood regime have a complex task: they must consider several interdependent issues referenced in multiple non-coordinated laws. Diverse actors are legally mandated to consider multiple issues across legal acts, their portfolios become increasingly complex, and the transaction costs associated with coordination increase as well. The high extent of the regime negatively 
affects its coherence by increasing the space for unexpected incoherencies between policies.

As an example, the Swiss Hydraulic Engineering Act (HEA) concentrates on a dominant infrastructure-based approach to flood protection. Nevertheless, protective constructions, corrections, or containment structures have created multiple negative impacts on biodiversity. In a 2011 response, the revised Water Protection Act introduced the goal of revitalizing watercourses toward a more natural state. Introducing one new policy on revitalization interacts with multiple preexisting policies that regulate interdependent issues. Revitalizing rivers is meant to offer a solution for both biodiversity losses and flood risks, but it also limits the possibilities for hydropower generation, which is dependent on some degree of water flow. Hydropower, in turn, is indispensable for the Swiss electricity mix, especially in times of the energy transition and nuclear phase-out. This revitalization-hydropower conflict illustrates that the introduction of a new policy brings to light multiple issue interdependencies and potential conflicts if the legal framework does not coordinate these interdependent issues. The Swiss flood-related laws, however, remain largely specialized on one or several similar issues (Metz et al., 2020). Hence, actors face conflicts of interest when implementing flood risk projects with lengthy negotiation processes, which potentially delay or even halt projects (Metz \& Glaus, 2019), highlighting the importance of an integrated legal framework.

A key loss in coherence comes through unanticipated policy interlinkages, which relate to interpolicy transaction costs associated with a contradiction between, and complexification of, procedures and other forms of policy interplays (Oberthür and Stokke 2011; Bolognesi \& Pflieger, 2019). Figure 7 shows how the expansion of the extent and the number of interlinkages between policies follow various dynamics (Hyp. 1). Further, we identify a shift in the regime evolution, marked by an exponential increase of issue-based interlinkages between legal documents over the years (Hyp. 2), which suggests that the regime has entered a phase characterized by an institutional complexity trap. The red line corresponds to the number of issue-based interlinkages between legal documents, i.e., the space for incoherencies, while the blue line represents the increase of existing legal documents, i.e., extent.

The figure shows that extent and the space for incoherence do not evolve on the same rhythm, confirming our first hypothesis. Between 1848 and 1978, extent expands while the number of policy interlinkages remains null, indicating that every new law regulates new issues separately. In reference to the ICT model, this period of time corresponds to the start and the early development phases of the evolution of the regime. Then, both the number of laws and the policy interlinkages increase, yet the latter accelerate dramatically and disproportionally to the former. Therefore, extent impacts on coherence nonlinearly (Hyp. 2), supporting the relevance of the systemic perspective to understand integration and its evolution (Biesbroek and Candel 2019; Bolognesi \& Nahrath, 2020; Candel \& Biesbroek, 2016). The period 1990-1992 marks a turning point in the evolution of the regime. The number of interlinkages continues to increase dramatically. From 1992, the increase of interlinkages between policies (i.e., space for incoherence) is faster than the growing number of policy instruments (extent) itself.

Our results show that in 2010, the average ratio of interlinkages per legal document was 3.05 (174 interlinkages between the 57 existing policy documents), while this ratio was of 2 in 2000 (100 interlinkages between the 50 existing laws), of 0.25 in 1990 (6 interlinkages between the 24 existing laws), and equal to 0 in 1977 (no interlinkages between the 17 existing laws), thereby confirming our second hypothesis. We observe that the regime is falling into an institutional complexity trap (Bolognesi \& Nahrath, 2020). 


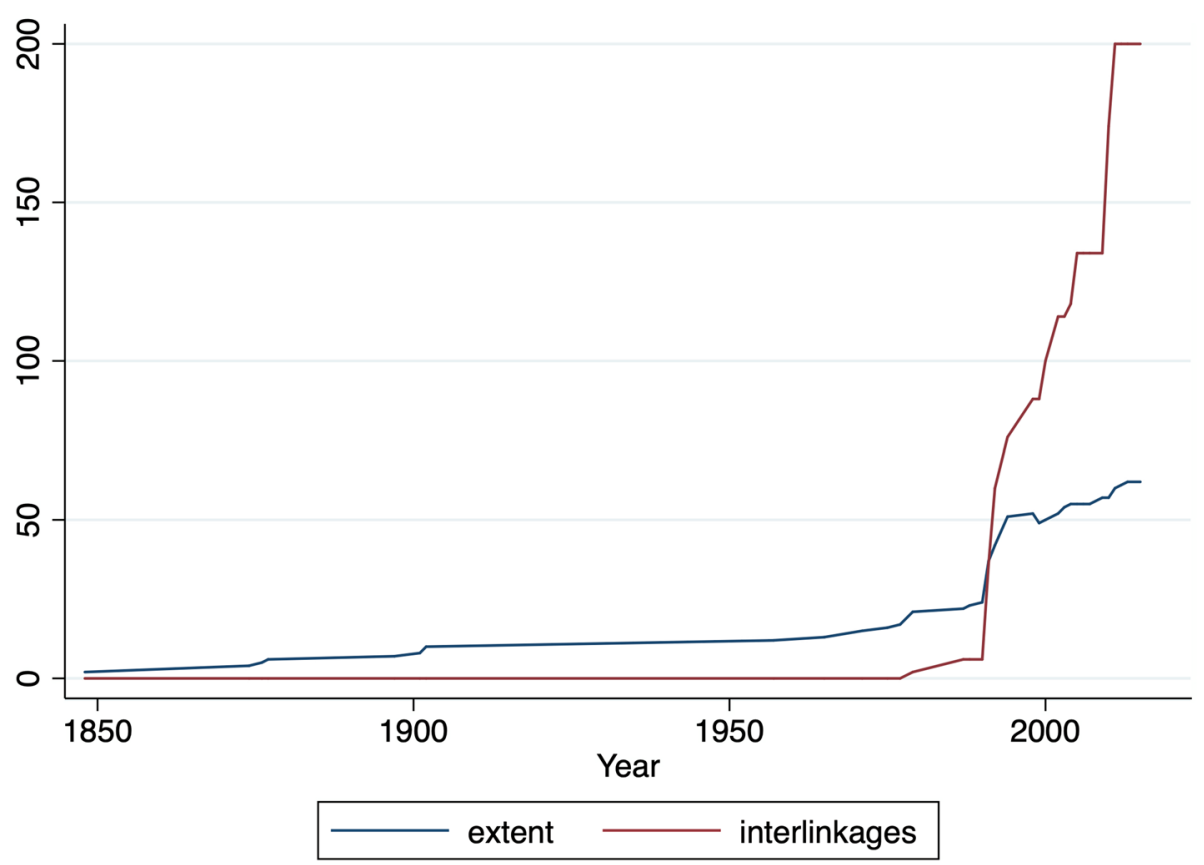

Fig. 7 Evolution of the number of policy instruments (extent, blue line) and interlinkages between policies (space for incoherencies, red line)

In summary, we depict below that those empirical findings confirm our hypotheses. We observe an expansion of extent over time. Comparing this expansion with the space for incoherence, i.e., policy interlinkages, confirms that extent affects coherence nonlinearly (H1), and that the evolution of the regime reaches a tipping point where the number of interlinkages between legal documents, i.e., issue co-regulations, grows more than does extent (H2), characterizing the start of the ICT phase.

\section{The evolution of the regime as a system}

To offer a systemic perspective on the evolution of the Swiss flood regime, we link together its extent and coherence to infer information about its integration. It is worth reminding that while we have a direct observation of extent, we use issue-based policy interlinkages as a proxy for coherence. We do not observe the integration process per se because it is defined as the combination of extent and coherence. The evolutionary pattern we present in this section is a simulation. As such, it must be interpreted as a heuristic model dedicated to ease and frame our understanding of the integration process.

In previous sections, we focused on the negative effect of extent on coherence, using a network approach to issue-based policy interlinkages. To infer the evolution of integration, we also take into account the positive effect that coherence has on integration. Trialand-error learning and Darwinist competition are two processes that improve coherence and coordination (Challies et al., 2017; Gerlak et al., 2018; Hodgson \& Knudsen, 2010; Ostrom, 2005). To identify these two positive processes, we focus on the abolishment of policy instruments through which the extent of the regime decreases. 


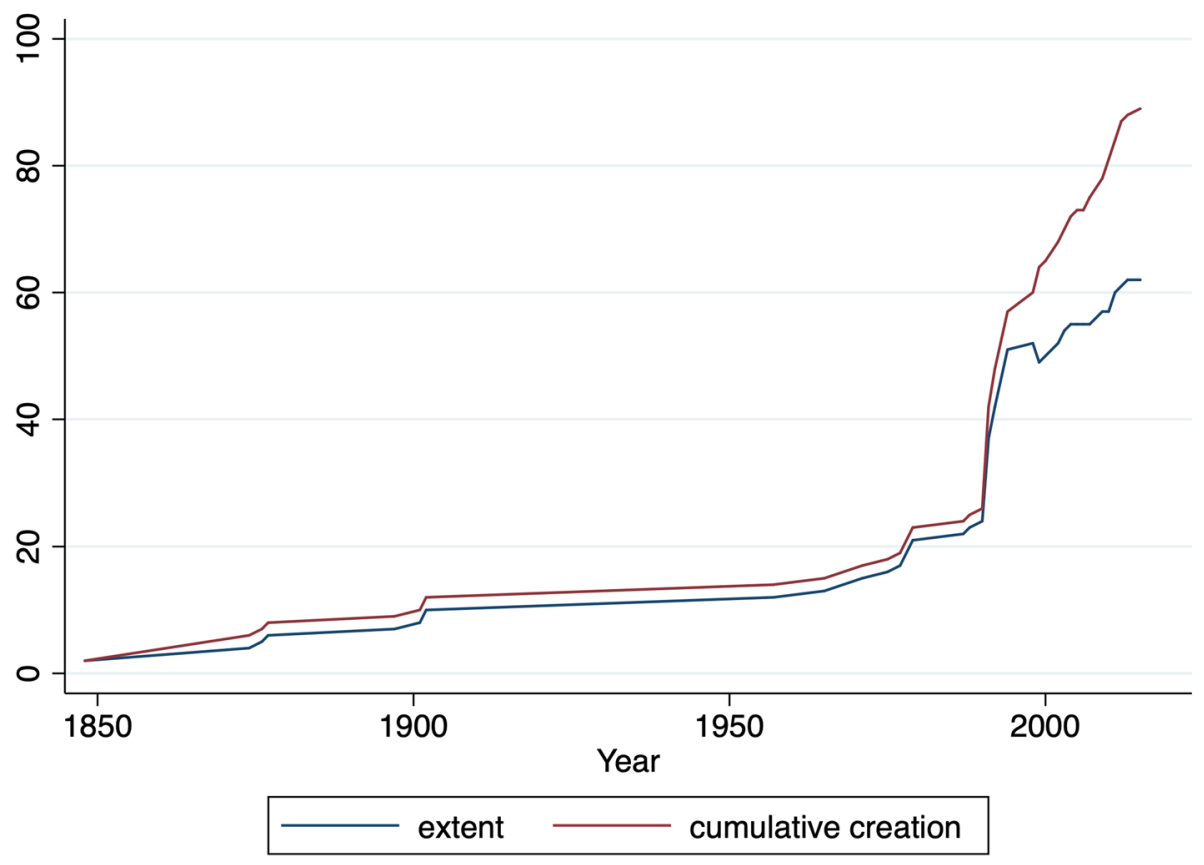

Fig. 8 Evolution of the total number of adopted policy instruments (cumulative creation in red) and instruments in force (net policy instruments accumulation in blue) in the Swiss flood regime since 1848

Figure 8 compares the total number of policy instruments that have been adopted since 1848 (red line) with the total number of policy instruments that are still in force (blue line). The difference between the two represents the number of policy instruments that have been adopted and then abolished since 1848. Policy makers may decide, for instance, to abolish obsolete policy instruments or to substitute them for more efficient ones. We interpret the difference between the lines as a search for coherence among instruments that lead to refine and transform policies (Challies et al., 2017; Gerlak et al., 2018). Our findings show that since the late 1990s, the Swiss flood regime was reorganized in order to improve its coherence and promote integration. This trend parallels the evolution of other water regimes in Europe (Bolognesi, 2014; Colon, Richard, and Roche 2017; Kissling-Näf \& Kuks, 2004; Varone et al., 2002) and highlights the positive dynamic of coherence in the integration process.

Comparing the growth of policy interlinkages with the search for coherence sheds light on the integration dynamics in the long run. This juxtaposition also puts forward that the increase in policy interlinkages, i.e., the indirect negative impact that the extent has on coherence, occurs at a faster rate than does the search for policy coherence. Consequently, the regime is locked into an Institutional Complexity Trap.

Figure 9 portrays these two opposing dynamics: the attempt to increase coherence versus the persistence of incoherencies due to the increase in unexpected policy interlinkages (structural change). We map the expected evolution of coherence as a function of abolished policy instruments and the evolution of policy interlinkages. The blue line represents the change in coherence over time (global change), while the red spikes refer to the yearly change in coherence (marginal change), i.e., the number ties added or removed by each new policy. Results confirm our third hypothesis. We observe that the loss of coherence 


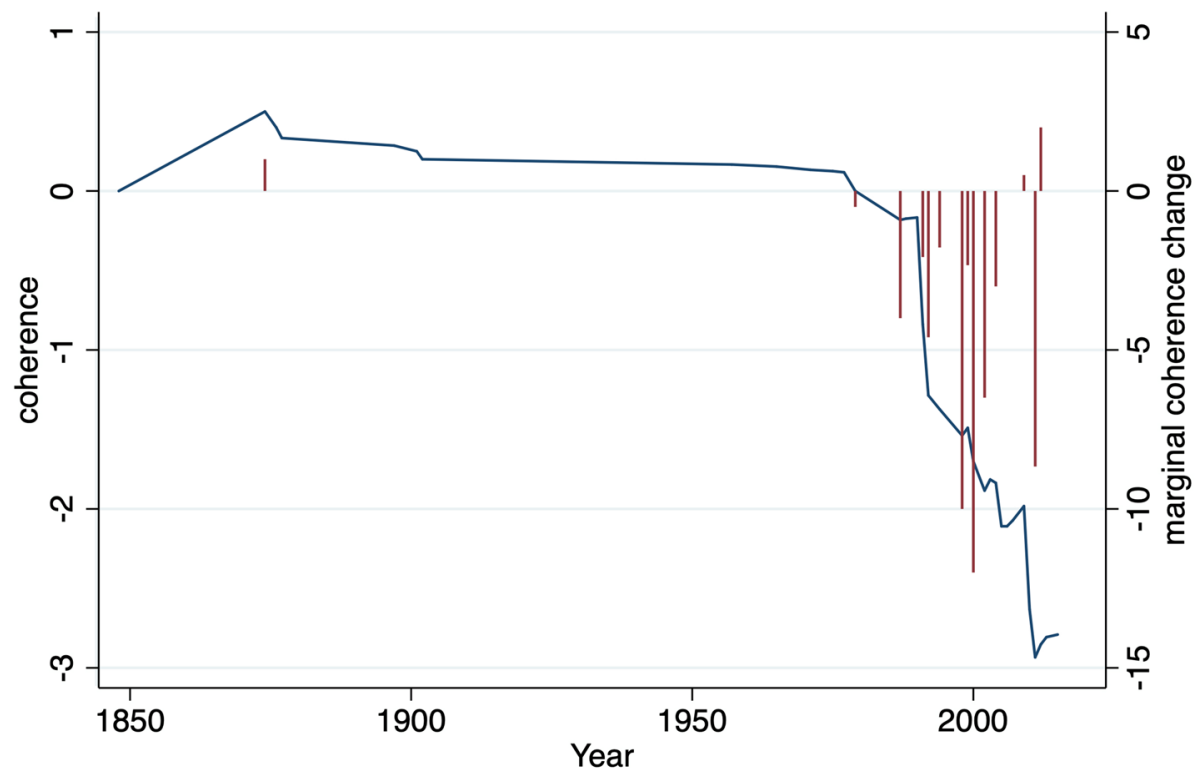

marginal coherence change

Fig. 9 Coherence evolution over the years (global change, blue, left) and yearly (marginal change, red, right). Note: We do not measure coherence directly but through the room that the growing number of policy interactions make for incoherence. Consequently, attention should be placed on the shape of the curve as opposed to the values. We appraise coherence change by comparing the share of abolished policies in the regime to the density of policy interlinkages over years, formally, for each period starting from year 1848 to year $t: \frac{\text { abolished PP }}{\text { promulgated PP }}-\frac{\text { edges }}{\text { extent }}$. This measurement reflects coherence as it intends to grasp the importance of the policy learning and selection processes, assuming that abolished policy instruments reflect this process.

due to issue-based policy interlinkages (i.e., the ICT effect reflecting the structural change of the regime), is stronger than the attempts of policy actors to improve coherence. As a result, the blue line shows that coherence globally decreases even if punctuated by some improvements of coherence that may slow down disintegration but do not stop the downward trend altogether.

Our findings indicate that the Swiss flood regime went through three different phases, the first of which started in 1848 and constituted the birth of the regime. This phase ended in 1874 , when the first readjustments were made in the regime. In 1874, two policy instruments were abolished and four new ones were promulgated, thereby illustrating a trial-error process: the actors adjusted governance to its context. The second phase (1874-1991) corresponds to the development of the regime. 33 new policy instruments were adopted, when only three were abolished. Extent represents the key driver of integration. During the third phase, there is a search for coherence, and the proportion of abolished policy instruments to the total number of adopted policy instruments jumps from $7.69 \%$ in 1990 to $30.34 \%$ in 2015. Our findings highlight that the evolution of the regime is still perceived by the policy makers as needing to go through an expansion of its scope (extent), although they have been paying increasing attention to coherence. 


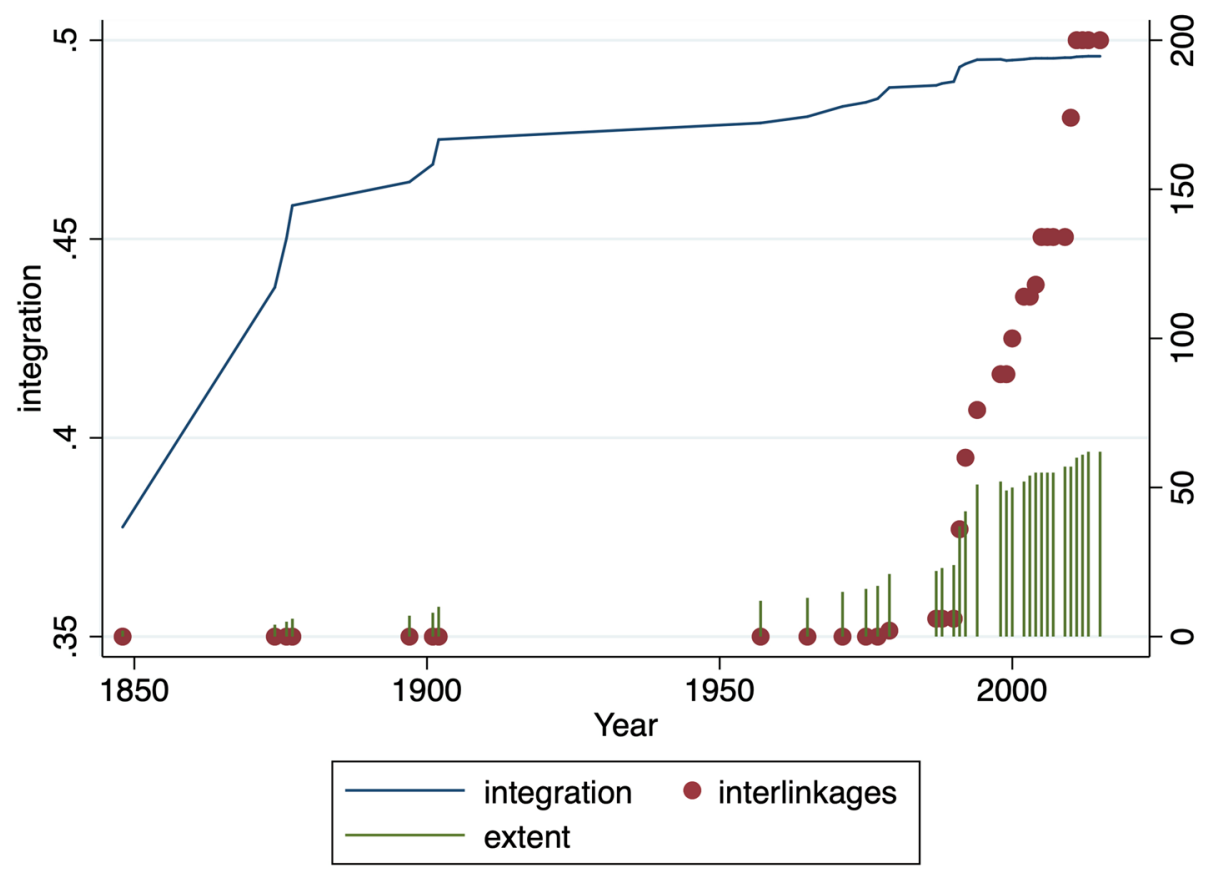

Fig. 10 Extrapolation of integration of the Swiss flood policy regime (blue line) from its extent (green spikes) and policy interlinkages (red dots). Note: interlinkages reflect coherence, so the figure assembles the three key variables of the ICT model to show the integration process

\section{Extrapolation of the integration pattern}

Finally, we take advantage of the formal definition of integration as a function of extent proposed by Bolognesi and Nahrath (2020) to illustrate the systemic dynamic of integration and to highlight the emergence of an Institutional Complexity trap. We use the evolution of extent and interlinkages to extrapolate the evolution of the Swiss flood regime's integration from 1840 to 2016 (Fig. 10). The blue curve represents the shape of the evolution of the regime's integration as a function of its extent, considering both the positive direct and negative indirect impacts. The green spikes indicate the number of policy instruments, i.e., the regime extent, and the red dots the number policies interlinkages, i.e., the proxy for policy (in) coherence.

The figure depicts the nonlinearities and disconnections between the growth of extent and policy interlinkages, as well as the respective impact of both on the evolution of the regime's integration. The extrapolation enables one to bound in time the different phases of the regime with reference to the ICT model. The first phase (the "start") lasted from 1848 until 1874, when extent started to increase. From 1874 to the 1990 s, we observe the "development" of the regime during which the increase of extent drove the regime's integration. We observe that the integration curve becomes continuously less steep, highlighting the emergence of potential incoherencies. Since the 1990s, the regime seems to have experienced an Institutional Complexity Trap. The increase in integration is not significant despite the substantial expansion of extent. Indeed, throughout the same time window, the number of policy interlinkages escalates disproportionally, which suggests that numerous 
incoherencies arise and annihilate the positive effect of extent on integration. Beyond flood risk management, this sequence is consistent with observations about the evolution of water regimes in Switzerland and Europe (Bolognesi, 2018; Bolognesi \& Nahrath, 2020; Kissling-Näf \& Kuks, 2004; Reynard, Mauch, and Thorens 2000; Varone et al., 2002).

\section{Discussion and conclusion}

This paper focused on regime integration processes in relation to extent, i.e., the number of regulated issues, and coherence, i.e., the clarity of, and complementarity between, policies. Most of the literature in the field considers that extent affects integration positively; that is, the more regulated the issues, the more effective the coordination. We argue that this mechanism works only in the case that coherence remains constant.

In this paper, we lift the assumption that coherence remains constant and instead show that extent has an ambiguous effect on integration due to two conflicting mechanisms. On the one hand, the expansion of extent contributes to integration, which is consistent with the literature's assumptions. On the other hand, however, a high extent produces unexpected interlinkages between policy documents, which has the effect of reducing coherence, and subsequently, of regime integration. These unexpected interlinkages catalyze conflicting overlaps and specific transaction costs, lessening the clarity of the regime and the level of complementarity between its components. Testing these mechanisms allows for appraising the empirical validity of the Institutional Complexity Trap model (Bolognesi \& Nahrath, 2020), and, more broadly, for the effectiveness of polycentricity, policy integration, and institutional complementarity (Aoki, 2007; Berardo \& Lubell, 2016; Crouch et al., 2005; Ostrom, 2005; Trein et al. 2021).

We have presented the results of a relational analysis we carried out with regard to the policy that were created and abolished in the Swiss flood regime between 1848 and 2016. The data we have collected allow to measure the evolution of unexpected interlinkages between policy documents (our proxy for coherence) and the number of policy instruments (our proxy for the extent). Policy interlinkages constitute a reliable proxy for coherence as it sets the room for unexpected transaction costs and potential non-complementarities between policies.

We scrutinized the systemic dynamics of integration in the long run and put forward that the negative effect that the extent has on coherence is instrumental and dramatically limits the ability to reach higher degrees of integration by expanding the regime extent. It is of paramount importance for practice and the study of policy effectiveness as it contributes to explain the current paradox of policy regimes that falls short in expectations while composed of a priori well-designed policies. This general conclusion stands on three key findings.

As a first key finding, we noted that the evolution of interlinkages between policy documents is independent from the growth of the number of policy instruments (H1). Secondly, we identified a turning point from which the number of public policies is growing less rapidly than the number of their interlinkages $(\mathrm{H} 2)$. Consequently, the common assumption that coherence remains constant is no longer tenable. The coherence of the regime is significantly affected by the evolution of its extent. We argue that the combination of these two mechanisms explains the nonlinearities of the policy integration in the long run, although they remain seldom investigated (Adam, Hurka, Knill, Peters, et al. 2019; Bolognesi \& Nahrath, 2020; Candel \& Biesbroek, 2016; Trein et al. 2020). Results support the Institutional Complexity Trap model and contribute to the nascent explanations of policy disintegration through uncoordinated policy 
accumulation and lack of policy coherence (Adam et al., 2019a, 2019b; Biesbroek \& Candel, 2019; Cejudo \& Michel, 2021; Howlett, 2019; Limberg et al., 2021). The lack of policy coordination may have numerous causes; for example, conflicts among administrations or MP coalitions (Hustedt \& Danken, 2017), which contribute to the Institutional Complexity Trap. Conversely, the Institutional Complexity Trap could favor policymaking driven by political interests (Adam et al., 2018).

As a third key finding, we observed that the general trend toward disintegration is punctuated by discrete improvements of integration (H3) where adaptations are made to the regime by the policy makers in order to improve its coherence through trial-error processes and a Darwinist selection of policies (Hodgson \& Knudsen, 2010; Ostrom, 2005). This result paves the way for a dynamic perspective of integration that would be conceived in terms of embedded coherence cycles that may allow for unifying multiple theories of policy change. From a long-term perspective, regimes arrive at a saturation phase, namely the Institutional Complexity Trap. Within this long-term cycle, shorter cycles occur. They follow a policy adaptation logic, which contributes to slow down the ICT dynamic, but without the power to stop or reverse it altogether. This intertwinement of cycles raises the question of whether policy disintegration might be more effective. Indeed, policy disintegration may enable transformative changes instead of further developing a regime that loses coherence due to path dependency and the inability to make a complementary governance structure from past and future policies.

Our methodology offers an innovative way to appraise polycentricity and policy integration with reference to policy coherence, which constitutes a long standing challenge in the field of policy studies (Cejudo \& Michel, 2017; May et al., 2006). Consistent and remarkable relational policy analyses have already been carried out in an attempt to understand policy process (Ingold et al., 2018; Leifeld, 2013; Lubell, Robins, and Wang 2014; Baggio et al., 2016; Morrison, 2017). In this paper, we have emphasized an approach that accounts for unexpected policy interlinkages. We identify co-regulations of policy issues and construct a law-law relational dataset. We have demonstrated that this method allows for approximating the room for incoherencies between policies. We believe that it is a promising avenue for addressing the challenge of measuring policy coherence over time. Further qualifying the nature of the interlinkages offers an even more accurate observation of the degree of coherence (Heikkila \& Weible, 2018; Metz et al., 2020).

At the same time, however, this method does not come without pitfalls. We chose not to analyze policy content. This approach impedes directly observing the complementarities or incoherencies in each interlinkage. This limitation is common in the literature and our relying assumption that, on average, a growing number of interlinkages mainly includes incoherence is highly plausible, for instance because the relations among policy instruments are often unintentional ("Appendix 2"). Consequently, our findings are reliable but further fine-grained analyses would be needed in order to overcome this methodological challenge. We believe that using Ostrom's institutional grammar, or the narrative policy framework (Jones \& McBeth, 2010), could contribute to overcoming these methodological limitations as well as to helping validate our theoretical proposition.

A second pitfall of our research includes the external validity of the results. Building such a precise policy interlinkages dataset requires considerable work. We could only cover one regime and therefore could not proceed to a cross-sectoral comparative analysis. Future research that replicates this analysis and compares findings is needed. Nonetheless, previous case studies (Kissling-Näf \& Kuks, 2004; Lieberherr et al., 2019) and recent research on the Institutional Complexity Trap (Bolognesi \& Nahrath, 2020b; Bolognesi \& Pflieger, 2019) confirm our results and suggest that further generalization could be possible. 
Additionally, our results focus on public policies and do not consider private property rights here. Following Bolognesi and Nahrath (2020) and Bolognesi and Pflieger (2019), we can reasonably presume that private property rights would increase the magnitude of the negative, although indirect, impact of extent on integration. Public policies have constituted an ex-post regulation of property rights, especially since the 1980s (e.g., Varone \& Nahrath, 2014). The process of property rights unbundling is a source of systemic incoherence because of contractual incompleteness (Brousseau, 2008).

Our results signify that the policy makers' work becomes increasingly complicated over time, not only because of the growing number of relevant laws, but also because of the growing number of interlinkages between the policy documents. Future research could include the following questions: How do the actors handle these complexities when formulating policies? What mechanisms could address ICTs? What are the best strategies for supporting policy (instrument) coordination and limiting unexpected interlinkages between policy documents?

For policy makers - as well as for institutional economists and political scientiststhere is no doubt that providing answers to such critical issues aims to open the discussion to the contribution of legal scientists, particularly to experts in legistic (i.e., legislation drafting and evaluation). In fact, it is far from certain that the objective of reducing legal complexity could be achieved through a simple reduction of the volume of rules, and/or the "fusion" or "integration" of legal texts (laws and/or ordinances) (Flückiger, 2019). We have emphasized that improving regime coherence is of first importance, and given the ineffectiveness of the current patterns of extent-driven policy integration, novel approaches of (dis)integration deserve more attention.

\section{Appendix 1: Delineation of the perimeter of policy regime}

While there exists a vast literature on policy regime, here we provide a more precise definition of our use of the concept. Policy regime compounds public policies and property rights (Gerber et al., 2009; Vatn, 2005). We characterized a policy regime by its scope, the number of regulated issues, its coherence, and the clarity and fit of the policies within the regime.

\section{Focus on public policy}

We focus on public policies for the sake of empirical feasibility. For instance, the identification of all the existing property rights is a highly complex endeavor due to the networks of contracts. Nonetheless, including property rights in the analysis would reinforce the observed mechanisms. There is evidence that achieving coherence between public policies and property rights is challenging (Bolognesi \& Pflieger, 2019, Bolognesi, 2014; Fluckiger 2019). Corroborative evidence of the growing number of coherence issues between public policies and property rights includes the ongoing judicialization of developed economies (Hirshl 2011).

Producing coherence between private property rights and private property rights and public policies is a serious issue as new public management principles and the involvement of private sector in public services delivery, following liberalization processes, not only induce a multiplication of property rights, but also go deep into the provision of public services and goods. Indeed, public policies and property rights relate to distinctive judicial bodies with their own logics and notable dynamics (Aubin \& Varone, 2013; Bolognesi \& Nahrath, 2020; Gerber et al., 2009). 


\section{Politics and power}

Politics and power struggles are part of the policymaking and should therefore affect the processes of policy regime integration, i.e., changes in scope and coherence. At this stage in our research, we have decided to omit the impact of politics and power struggles for three main reasons.

First, politics and power struggles rely on different mechanisms and rationales than the one we scrutinize.

Second, we adopt a building-block approach of theory building (Knight, 1992). Knight (1992) argues that the understanding of institutional change is gradual, starting from naïve ontology to increased sophistication; the latter includes more social phenomena such as power and culture into the theory. We adopt a naïve ontology to offer a ground for a theory of integration dynamics.

Thirdly, and consequently, we argue that identification of the evolution of integration processes should come prior to the inclusion of politics in order to facilitate causal hypotheses formulation and testing. For instance, the politics of complexity is likely to affect coherence in a nonlinear way (Alter \& Meunier, 2009), and we argue that institutional evolution of integration is nonlinear as well. To handle integration processes, we believe that the nonlinearities in policy regime evolution, which are structural, should be immediately identified and understood. The next step would then include an explanation for how politics, and its many spatial and temporal contingencies, contributes to and interacts with the institutional pattern. Intuitively, we expect that the Institutional Complexity Trap widens the space for the politics of complexity.

\section{Appendix 2: Details on the network analysis}

See Table 2 and Fig. 11.

Table 2 Expected and unexpected interlinkages between policy instruments in the main Swiss flood policies (status in 2020)

\begin{tabular}{|c|c|c|c|c|c|c|c|c|c|}
\hline & $\begin{array}{ll}\text { HEA } & \text { (RS } \\
721.100)\end{array}$ & \begin{tabular}{|l|l}
$\mathrm{HEO}$ & (RS \\
$721.100 .1)$ &
\end{tabular} & \begin{tabular}{|l|l|} 
WRFO \\
$721.101 .1)$
\end{tabular} & \begin{tabular}{|l|} 
WPA \\
$814.20)$
\end{tabular} & $\begin{array}{ll}\text { ForO } & \text { (RS } \\
921.01)\end{array}$ & SPA (RS 700) & $\begin{array}{ll}\text { AlertO } \\
520.18)\end{array}$ & \begin{tabular}{|l|} 
ISA \\
$961.01)$
\end{tabular} & $\begin{array}{ll}\text { AlluvO } & \text { (RS } \\
451.31)\end{array}$ \\
\hline $\begin{array}{l}\text { HEA } \\
721.100) \\
\text { mentioned in.... }\end{array}$ & & 0 & 0 & \begin{tabular}{c|}
1 \\
$(=$ coordination $)$
\end{tabular} & 0 & 0 & 0 & 0 & 0 \\
\hline $\begin{array}{l}\text { HEO } \\
721.100 .1) \\
\text { mentioned in.... }\end{array}$ & 0 & & 0 & 0 & 0 & 0 & 0 & 0 & 0 \\
\hline $\begin{array}{l}\text { WRFO (RS } \\
721.101 .1) \\
\text { mentioned in.... }\end{array}$ & 0 & 0 & & 0 & 0 & 0 & $\begin{array}{c}1 \\
\text { (=coordination) }\end{array}$ & 0 & 0 \\
\hline $\begin{array}{l}\text { WPA } \quad \text { (RS } \\
814.20) \\
\text { mentioned in } \ldots . .\end{array}$ & 0 & $\begin{array}{c}1 \\
\text { (=coordination) }\end{array}$ & 0 & & 0 & 0 & 0 & 0 & 0 \\
\hline $\begin{array}{l}\text { ForO } \quad \text { RS } \\
921.01) \\
\text { mentioned in } \ldots . .\end{array}$ & 0 & 0 & 0 & 0 & & 0 & 0 & 0 & 0 \\
\hline $\begin{array}{l}\text { SPA (RS 700) } \\
\text { mentioned in.... }\end{array}$ & 0 & 0 & 0 & \begin{tabular}{c|}
2 \\
$(=$ coordination $)$
\end{tabular} & $\begin{array}{c}4 \\
\text { (=coordination, } \\
\text { but not relating } \\
\text { to flood } \\
\text { protection })\end{array}$ & & 0 & 0 & 0 \\
\hline $\begin{array}{l}\text { AlertO } \quad \text { (RS } \\
520.18) \\
\text { mentioned in.... }\end{array}$ & 0 & 0 & 0 & 0 & 0 & 0 & & 0 & 0 \\
\hline $\begin{array}{l}\text { ISA } \quad \text { (RS } \\
961.01) \\
\text { mentioned in.... }\end{array}$ & 0 & 0 & 0 & 0 & 0 & 0 & 0 & & 0 \\
\hline $\begin{array}{l}\text { AlluvO (RS } \\
451.31) \\
\text { mentioned in.... }\end{array}$ & 0 & 0 & 0 & 0 & 0 & 0 & 0 & 0 & \\
\hline
\end{tabular}

Legend: AlertO=Alerting- and Security Ordinance; AlluvO=Alluvial Areas Protection Ordinance; ForO $=$ Forest Ordinance; HEA $=$ Hydraulic Engineering Act; HEO $=$ Hydraulic Engineering Ordinance; ISA = Insurance Supervision Act; SPA =Spatial Planning Act; WPA = Waters Protection Act; $\mathrm{WRFO}=$ Water Retaining Facilities Ordinance 
Fig. 11 Evolution of the policy instruments network in Swiss flood risk management since 1848. Note: gray edges $=$ linkages already present in previous phase; red edges = new linkages created between 1990 and 2000 or 2000 and 2010. Legend: AlertO=Alerting- and Security Ordinance, AlluvO=Alluvial Areas Protection Ordinance, Fconst $=$ Federal Constitution of the Swiss Confederation, for $a=$ Forest Act, ForO $=$ Forest Ordinance, HEA = Hydraulic Engineering Act, HEO=Hydraulic Engineering Ordinance, ISA = Insurance Supervision Act, ISO = Insurance Supervision Ordinance, NCHA = Nature and Cultural Heritage Act, $\mathrm{NCHO}=$ Nature and Cultural Heritage Ordinance, $\mathrm{NEOCO}=$ Ordinance of the National Emergency Operations Centre, PCPA = Population- and Civil Protection Act, SPA = Spatial Planning Act, SPO=Spatial Planning Ordinance, WPA $=$ Waters Protection Act, WPO $=$ Water Protection Ordinance, WRFA $=$ Water Retaining Facilities Act, WRFO = Water Retaining Facilities Ordinance

\section{Negative versus positive effect of policies' interlinkages}

In this paper, we assume that the interlinkages between policies are subject to transaction costs and that on average the negative effect of these interlinkages is higher than the positive outcome. This assumption is plausible because our data include the unexpected interlinkages where transaction costs are higher (Bolognesi \& Nahrath, 2020; Bolognesi \& Pflieger, 2019) and temporal interactions not coordinated (Cejudo \& Michel, 2021; Howlett, 2019), while most of the literature focuses on intentional ties (Persson et. al. 2018; Trein and Maggetti 2020 This assumption is subject to a risk of overestimation of the coherence loss as the regime scope expands. Nevertheless, we argue and have evidence that this risk is less important than the one associated with the alternative assumption. According to our findings, the only way to accurately weigh the proportion of negative and positive effect is to carry out an in-depth content analysis for each policy.

We chose not to base the proposed relational approach on a content analysis of public policies in order to respect the parsimony and replicability criteria that founds the reliability of our analysis. Indeed, a content analysis of coherence in the long run faces two important pitfalls. On the one hand, it involves strong assumptions about coherence that are not objective (May, Sapotichne and Workmann 2006). And on the other hand, such a content analysis is hardly feasible. Furthermore, as several case studies demonstrate, positive interlinkages are more likely to represent the exception than the rule due to the policy regime complexity (Adam et al., 2018; Biesbroek \& Candel, 2020; Varone and Narath 2014). In fact, incoherencies due to unexpected interlinkages are much more likely to occur, as illustrated in our specific case in the next subsection of the appendix.

\section{Empirical evidence for the unexpectedness of the policy interlinkages}

Table 2 portrays the number of expected (coding $=1,2$, or 4$)$ and unexpected $(\operatorname{coding}=0)$ interlinkages between all the policy instruments included in the 9 main laws and ordinances constitutive of the Swiss flood policies in the current status (2020). We consider the case of an explicit coordination between two legal texts regarding a specific policy instrument as an expected interlinkage. Based on a conservative perspective, however, we adopt a rather broad definition of coordination. Indeed, we consider that coordination exists as soon as a legal text (law or ordinance) makes a reference to another legal text, whether to its policy objectives, principles, or instruments. We consider the case where there is no mention of another legal text constitutive of the flood policies to be an unexpected interlinkage. We used two main criteria for selecting the 9 main legal texts constitutive of the Swiss flood policies: (1) the density of policy instruments' interlinkages in which they are imbedded 


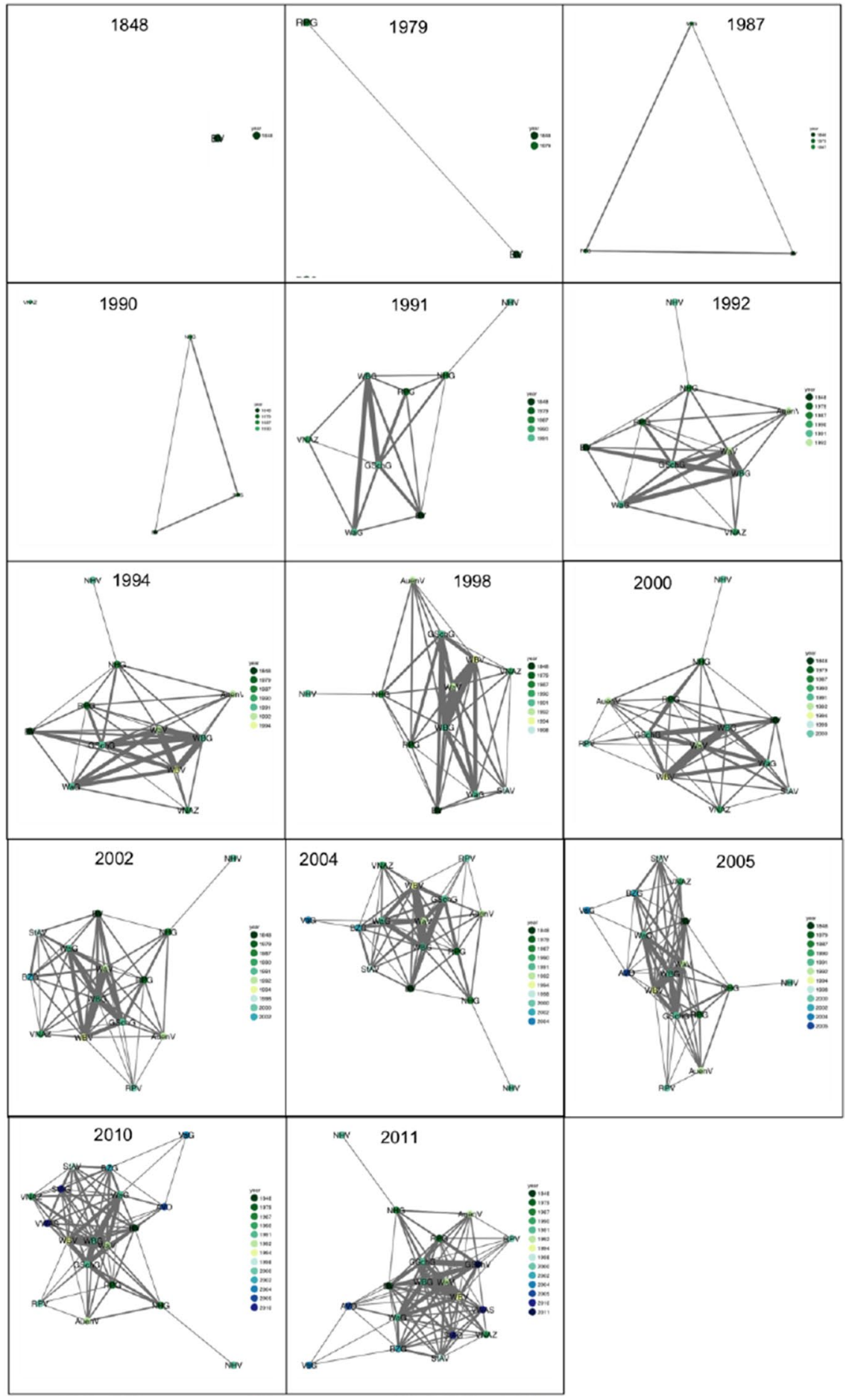


and the degree of centrality in the network, and (2) a mix of ancient (before 2000) and new (adoption between 2000 and 2010) legal texts.

The table clearly depicts that there is very little coordination between the 9 main legal texts constitutive of Swiss flood policies. Indeed, a vast majority of laws and ordinances do not make any reference to one or the other legal text of the Swiss flood policies corpus (67 cells are coded 0 ). Out of a total of 9 situations of coordination between policy instruments, only 5 refer to flood protection, which clearly means that a vast majority of the interlinkages between policy instruments are unexpected.

\section{Identification of the policy instruments}

The analysis focuses on 89 policy instruments. They have been classified according to the generic policy instrument types and policy approaches to which they belong. They have been categorized according to three generic policy instrument types (Metz \& Glaus, 2019), which are 1) regulatory policy instruments (e.g., prohibitions and requirements), 2) (financial) incentives, and 3) voluntary policy instruments. Out of the 89 policy instruments that form our dataset, we have identified 78 regulatory policy instruments, 8 (financial) incentives, and 3 voluntary policy instruments. Historically, these 89 instruments have been progressively developed and implemented as part of 7 different policy approaches (or causal models) that were introduced successively between 1848 and 2017 and are now constitutive of the current Swiss flood PR (see Fig. 2). These policy approaches (or causal models) have been entitled: (1) emergency/civil protection, (2) environmental protection, (3) infrastructure, (4) insurance, (5) maintenance, (6) monitoring, and (7) spatial planning.

\section{Detailed evolution of policy instruments' interlinkages}

Figure 11 presents the evolution of the interlinkages between policy instruments since 1848 until 2011 to portray the nonlinear complexification of the flood policy regime in Switzerland. The emergence of the Institutional Complexity Trap is noticeable since 1994.

Acknowledgements We acknowledge the editor and the anonymous reviewers for their valuable comments and remarks. We also thank Robbert Biesbroek, Guillermo Cejudo, Klaus Eisenack Manuel Fischer, Karin Ingold, Eva Lieberherr, Martino Maggetti, Philipp Trein and Sergio Villamayor-Tomas, and the audiences at the International Workshop on Public Policy (2019), Swiss Political Science Association annual congress (2020), European Consortium for Political Research general conference (2021), Ecole Nationale Supérieure Lyon (lab. EVS) workshop, International Association for the Study of the Commons conference on Polycentricity (2021) and Earth System Governance conference (2021) for useful and stimulating discussions and comments.

Funding Open access funding provided by University of Geneva.

Open Access This article is licensed under a Creative Commons Attribution 4.0 International License, which permits use, sharing, adaptation, distribution and reproduction in any medium or format, as long as you give appropriate credit to the original author(s) and the source, provide a link to the Creative Commons licence, and indicate if changes were made. The images or other third party material in this article are included in the article's Creative Commons licence, unless indicated otherwise in a credit line to the material. If material is not included in the article's Creative Commons licence and your intended use is not permitted by statutory regulation or exceeds the permitted use, you will need to obtain permission directly from the copyright holder. To view a copy of this licence, visit http://creativecommons.org/licenses/by/4.0/. 


\section{References}

Adam, C., Hurka, S., Christoph Knill, B., Peters, G., \& Steinebach, Y. (2019a). Introducing Vertical Policy Coordination to Comparative Policy Analysis: The Missing Link between Policy Production and Implementation. Journal of Comparative Policy Analysis: Research and Practice. https://doi.org/10. 1080/13876988.2019.1599161

Adam, C., Hurka, S., Knill, C., \& Steinebach, Y. (2019b). Policy Accumulation and the Democratic Responsiveness Trap. Cambridge University Press.

Adam, C., Steinebach, Y., \& Knill, C. (2018). Neglected Challenges to Evidence-Based Policy-Making: The Problem of Policy Accumulation. Policy Sciences, 51(3), 269-290. https://doi.org/10.1007/ s11077-018-9318-4

Al-Saidi, M., \& Elagib, N. A. (2017). Towards Understanding the Integrative Approach of the Water, Energy and Food Nexus. Science of the Total Environment, 574(January), 1131-1139. https://doi.org/ 10.1016/j.scitotenv.2016.09.046

Alter, K. J., \& Meunier, S. (2009). The Politics of International Regime Complexity. Perspectives on Politics, 7(1), 13-24.

Anderies, J. M., \& Janssen, M. A. (2013). Robustness of Social-Ecological Systems: Implications for Public Policy. Policy Studies Journal, 41(3), 513-536. https://doi.org/10.1111/psj.12027

Angst, M. (2018). Bottom-Up Identification of Subsystems in Complex Governance Systems. Policy Studies Journal (early View). https://doi.org/10.1111/psj.12301

Aoki, M. (2007). Endogenizing Institutions and Institutional Changes. Journal of Institutional Economics, 3(1), 1-31. https://doi.org/10.1017/S1744137406000531

Aubin, D., \& Varone, F. (2013). Getting Access to Water: Property Rights or Public Policy Strategies? Environment and Planning c: Government and Policy, 31(1), 154-167.

Baggio, J. A., BurnSilver, S. B., Arenas, A., Magdanz, J. S., Kofinas, G. P., \& De Domenico, M. (2016). Multiplex Social Ecological Network Analysis Reveals How Social Changes Affect Community Robustness More than Resource Depletion. Proceedings of the National Academy of Sciences, 113(48), 13708-13713. https://doi.org/10.1073/pnas.1604401113

Baumgartner, F. R., Christian, B., Christoffer, G.-P., Jones, B. D., Mortensen, P. B., Michiel, N., \& Stefaan, W. (2009). Punctuated Equilibrium in Comparative Perspective. American Journal of Political Science, 53(3), 603-620. https://doi.org/10.1111/j.1540-5907.2009.00389.x

Berardo, R., \& Lubell, M. (2016). Understanding What Shapes a Polycentric Governance System. Public Administration Review, 76(5), 738-751. https://doi.org/10.1111/puar.12532

Bergsma, E. (2018). Expert-Influence in Adapting Flood Governance: An Institutional Analysis of the Spatial Turns in the United States and the Netherlands. Journal of Institutional Economics, 14(3), 449-471. https://doi.org/10.1017/S1744137416000552

Biesbroek, R., \& Candel, J. J. L. (2019). Mechanisms for Policy (Dis)Integration: Explaining Food Policy and Climate Change Adaptation Policy in the Netherlands. Policy Sciences, June. https://doi. org/10.1007/s11077-019-09354-2

Biesbroek, R., \& Candel, J. J. L. (2020). Mechanisms for Policy (Dis)Integration: Explaining Food Policy and Climate Change Adaptation Policy in the Netherlands. Policy Sciences, 53, 61-84.

Bolognesi, T. (2014). The Paradox of the Modernisation of Urban Water Systems in Europe: Intrinsic Institutional Limits for Sustainability. Natural Resources Forum, 38(4), 270-281. https://doi.org/ $10.1111 / 1477-8947.12052$

Bolognesi, T. (2018). Modernization and Urban Water Governance: Organizational Change and Sustainability in Europe. Palgrave Macmillan UK. https://doi.org/10.1057/978-1-137-59255-2

Bolognesi, T., \& Nahrath, S. (2020). Environmental Governance Dynamics: Some Micro Foundations of Macro Failures. Ecological Economics, 170, 10655. https://doi.org/10.1016/j.ecolecon.2019. 106555

Bolognesi, T., \& Pflieger, G. (2019). The Coherence(s) of Institutional Resource Regimes: Typology and Assessments from the Case of Water Supply Management. Environmental Science \& Policy, 99, 17-28. https://doi.org/10.1016/j.envsci.2019.05.003

Brandenberger, L., Ingold, K., Fischer, M., Schläpfer, I., \& Leifeld, P. (2020). Boundary Spanning Through Engagement of Policy Actors in Multiple Issues. Policy Studies Journal Early View. https://doi.org/10.1111/psj.12404

Brousseau, Eric. (2008). Contracts: From Bilateral Sets of Incentives to the Multi-Level Governance of Relations. In E. Brousseau \& J. M. Glachant (Eds.), New Institutional Economics: A Guidebook (pp. 37-66). Cambridge: Cambridge University Press.

Candel, J. J. L. (2017). Holy Grail or Inflated Expectations? The Success and Failure of Integrated Policy Strategies. Policy Studies, 38(6), 519-552. https://doi.org/10.1080/01442872.2017.1337090 
Candel, J. J. L., \& Biesbroek, R. (2016). Toward a Processual Understanding of Policy Integration. Policy Sciences, 49(3), 211-231. https://doi.org/10.1007/s11077-016-9248-y

Capano, G., \& Galanti, M. T. (2018). Policy Dynamics and Types of Agency: From Individual to Collective Patterns of Action. European Policy Analysis, 4(1), 23-47. https://doi.org/10.1002/epa2.1031

Capano, G., \& Lippi, A. (2017). How Policy Instruments Are Chosen: Patterns of Decision Makers. Choices'. Policy Sciences, 50(2), 269-293. https://doi.org/10.1007/s11077-016-9267-8

Carlisle, K., \& Gruby, R. L. (2019). Polycentric Systems of Governance: A Theoretical Model for the Commons. Policy Studies Journal, 47(4), 927-952. https://doi.org/10.1111/psj.12212

Cejudo, G. M., \& Michel, C. L. (2017). Addressing Fragmented Government Action: Coordination, Coherence, and Integration. Policy Sciences, 50(4), 745-767. https://doi.org/10.1007/s11077-017-9281-5

Cejudo, G. M., \& Michel, C. L. (2021). Instruments for Policy Integration: How Policy Mixes Work Togethe. SAGE Open, 11(3), 21582440211032160.

Challies, E., Newig, J., Kochskämper, E., \& Jager, N. W. (2017). Governance Change and Governance Learning in Europe: Stakeholder Participation in Environmental Policy Implementation. Policy and Society, 36(2), 288-303. https://doi.org/10.1080/14494035.2017.1320854

Colon, M., Richard, S., \& Roche, P. A. (2017). The Evolution of Water Governance in France from the 1960s: Disputes as Major Drivers for Radical Changes within a Consensual Framework. Water International (early View). https://doi.org/10.1080/02508060.2018.1403013

Crouch, C., Streeck, W., Boyer, R., Amable, B., Hall, P. A., \& Jackson, G. (2005). Dialogue on "Institutional Complementarity and Political Economy." Socio-Economic Review, 3(2), 359-382. https://doi.org/10. 1093/SER/mwi015

Dupont, C., \& Jordan, A. (2021). 'Policy Integration'. In A. Jordan, \& V. Gravey (Eds.), Environmental Policy in the EU: Actors, Institutions and Processes (4th ed.). Routledge.

Feiock, R. C. (2013). The Institutional Collective Action Framework. Policy Studies Journal, 41(3), 397425. https://doi.org/10.1111/psj.12023

Feiock, R. C., Krause, R. M., \& Hawkins, C. V. (2017). The Impact of Administrative Structure on the Ability of City Governments to Overcome Functional Collective Action Dilemmas: A Climate and Energy Perspective. Journal of Public Administration Research and Theory, 27(4), 615-628. https://doi.org/ 10.1093/jopart/mux021

Fischer, M., \& Sciarini, P. (2016). Drivers of Collaboration in Political Decision Making: A Cross-Sector Perspective. The Journal of Politics, 78(1), 63-74. https://doi.org/10.1086/683061

Flückiger, A. (2019). (Re-)faire la loi: Traité de légistique à l'ère du droit souple. Staempfli Verlag.

FOEN. (2013). Swiss Environmental Law. A Brief Guide. Federal Office for the Environment.

FOWG. (2001). 'Hochwasserschutz an Fliessgewässern, Wegleitung Des BWG'. Bern, Switzerland: Federal Office for Water and Geology.

FOWG. (2002). Hochwasserschutz. Mehr Raum Für Die Fliessgewässer, Aquaterra, 1, 1-16. Bern, Switzerland.

Garrick, D., Whitten, S. M., \& Coggan, A. (2013). Understanding the Evolution and Performance of Water Markets and Allocation Policy: A Transaction Costs Analysis Framework. Ecological Economics, 88, 195-205. https://doi.org/10.1016/j.ecolecon.2012.12.010

Gerber, J.-D., Knoepfel, P., Nahrath, S., \& Varone, F. (2009). Institutional resource regimes: Towards sustainability through the combination of property-rights theory and policy analysis. Ecological Economics, 68(3), 798-809. https://doi.org/10.1016/j.ecolecon.2008.06.013

Gerlak, A. K., Heikkila, T., Smolinski, S. L., Huitema, D., \& Armitage, D. (2018). Learning our way out of environmental policy problems: A review of the scholarship. Policy Sciences, 51(3), 335-371. https:// doi.org/10.1007/s11077-017-9278-0

Heikkila, T., \& Weible, C. M. (2018). A Semiautomated Approach to Analyzing Polycentricity. Environmental Policy and Governance, 28(4), 308-318. https://doi.org/10.1002/eet.1817

Hirschl, R. (2011). The Judicialization of Politics The Oxford Handbook of Political Science. London: Oxford.

Hodgson, G. M., \& Knudsen, T. (2010). Darwin's Conjecture: The Search for General Principles of Social and Economic Evolution. University of Chicago Press.

Howlett, M. (2009). Governance Modes, Policy Regimes and Operational Plans: A Multi-Level Nested Model of Policy Instrument Choice and Policy Design. Policy Sciences, 42(1), 73-89. https://doi.org/ 10.1007/s11077-009-9079-1

Howlett, M. (2019). Procedural Policy Tools and the Temporal Dimensions of Policy Design. International Review of Public Policy, 1(1), 27-45.

Howlett, M., \& Ramesh, M. (2014). The Two Orders of Governance Failure: Design Mismatches and Policy Capacity Issues in Modern Governance. Policy and Society, 33(4), 317-327. https://doi.org/10.1016/j. polsoc.2014.10.002 
Hustedt, T., \& Danken, T. (2017). Institutional Logics in Inter-Departmental Coordination: Why Actors Agree on a Joint Policy Output. Public Administration, 95(3), 730-743. https://doi.org/10.1111/padm. 12331

Ingold, K., Moser, A., Metz, F., Herzog, L., Bader, H.-P., Scheidegger, R., \& Stamm, C. (2018). Misfit between Physical Affectedness and Regulatory Embeddedness: The Case of Drinking Water Supply along the Rhine River. Global Environmental Change, 48, 136-150. https://doi.org/10.1016/j.gloen vcha.2017.11.006

Jochim, A. E., \& May, P. J. (2010). Beyond Subsystems: Policy Regimes and Governance. Policy Studies Journal, 38(2), 303-327. https://doi.org/10.1111/j.1541-0072.2010.00363.x

Jones, M. D., \& McBeth, M. K. (2010). A Narrative Policy Framework: Clear Enough to Be Wrong? Policy Studies Journal, 38(2), 329-353. https://doi.org/10.1111/j.1541-0072.2010.00364.x

Jordan, A., \& Lenschow, A. (2010). Environmental Policy Integration: A State of the Art Review. Environmental Policy and Governance, 20(3), 147-158. https://doi.org/10.1002/eet.539

Kim, S. Y., Swann, W. L., Weible, C. M., Bolognesi, T., Krause, R. M., Park, A. Y. S., Tang, T., Maletsky, K., \& Feiock, R. C. (2020). Updating the Institutional Collective Action Framework. Policy Studies Journal (early View). https://doi.org/10.1111/psj.12392

Kissling-Näf, I., \& Kuks, S. (Eds.). (2004). The Evolution of National Water Regimes in Europe. Springer, Netherlands. https://doi.org/10.1007/978-1-4020-2484-9

Knight, J. (1992). Institutions and Social Conflict. Cambridge University Press.

Kriesi, Hanspeter, and Alexander H. Trechsel. 2008. The Politics of Switzerland: Continuity and Change in a Consensus Democracy.

Lafferty, W., \& Hovden, E. (2003). Environmental Policy Integration: Towards an Analytical Framework. Environmental Politics, 12(3), 1-22. https://doi.org/10.1080/09644010412331308254

Leifeld, P. (2013). Reconceptualizing Major Policy Change in the Advocacy Coalition Framework: A Discourse Network Analysis of German Pension Politics. Policy Studies Journal, 41(1), 169-198. https://doi.org/10. 1111/psj.12007

Lieberherr, E., Fischer, M., \& Tschannen, A. (2019). Taking Stock of Institutional Resource Regime Research: A Meta-Analysis. Environmental Science \& Policy, 97, 81-89. https://doi.org/10.1016/j.envsci.2019.04. 003

Lijphart, Arend. 2012. Patterns of Democracy. London: Yale University Press. http://www.jstor.org/stable/j. $\mathrm{ctt} 32 \mathrm{bg} 23$.

Limberg, J., Steinebach, Y., Bayerlein, L., \& Knill, C. (2021). The More the Better? Rule Growth and Policy Impact from a Macro Perspective. European Journal of Political Research, 60(2), 438-454. https://doi. org/10.1111/1475-6765.12406

Lorrain, D. (2005). Urban Capitalisms: European Models in Competition. International Journal of Urban and Regional Research, 29(2), 231-267. https://doi.org/10.1111/j.1468-2427.2005.00583.x

Lubell, M. (2013). Governing Institutional Complexity: The Ecology of Games Framework. Policy Studies Journal, 41(3), 537-559. https://doi.org/10.1111/psj.12028

Lubell, M., Mewhirter, J. M., Berardo, R., \& Scholz, J. T. (2017). Transaction Costs and the Perceived Effectiveness of Complex Institutional Systems. Public Administration Review, 77(5), 668-680. https://doi. org/10.1111/puar.12622

Lubell, M., Robins, G., \& Wang, P. (2014). Network Structure and Institutional Complexity in an Ecology of Water Management Games. Ecology and Society. https://doi.org/10.5751/ES-06880-190423

Mahoney, J., \& Thelen, K. (Eds.). (2009). Explaining Institutional Change: Ambiguity, Agency, and Power. Cambridge University Press.

May, P. J., Sapotichne, J., \& Workman, S. (2006). Policy Coherence and Policy Domains. Policy Studies Journal, 34(3), 381-403. https://doi.org/10.1111/j.1541-0072.2006.00178.x

Metz, F., Angst, M., \& Fischer, M. (2020). Policy Integration: Do Laws or Actors Integrate Issues Relevant to Flood Risk Management in Switzerland? Global Environmental Change, 61, 101945. https://doi.org/10. 1016/j.gloenvcha.2019.101945

Metz, F., \& Glaus, A. (2019). Integrated Water Resources Management and Policy Integration: Lessons from 169 Years of Flood Policies in Switzerland. Water, 11(6), 1173. https://doi.org/10.3390/w11061173

Mewhirter, J., Lubell, M., \& Berardo, R. (2018). Institutional Externalities and Actor Performance in Polycentric Governance Systems. Environmental Policy and Governance, 28(4), 295-307. https://doi.org/10. 1002/eet.1816

Morrison, T. H. (2017). Evolving Polycentric Governance of the Great Barrier Reef. Proceedings of the National Academy of Sciences, 114(15), E3013-E3021. https://doi.org/10.1073/pnas.1620830114

Nilsson, M., \& Persson, A. (2003). Framework for Analysing Environmental Policy Integration. Journal of Environmental Policy \& Planning, 5(4), 333-359. https://doi.org/10.1080/1523908032000171648 
Oberthür, Sebastian, and Olav Schram Stokke, eds. 2011. Managing Institutional Complexity: Regime Interplay and Global Environmental Change. MIT Press. http://www.jstor.org/stable/j.ctt5hhn40.

Ostrom, Elinor. 2005. Understanding Institutional Diversity. Princeton: Princeton University Press. http://www. jstor.org/stable/j.ctt7s7wm.

Ostrom, E. (2010). Beyond Markets and States: Polycentric Governance of Complex Economic Systems. American Economic Review, 100(3), 641-672. https://doi.org/10.1257/aer.100.3.641

Persson, A., Runhaar, H., Karlsson-Vinkhuyzen, S., Mullally, G., Russel, D., \& Widmer, A. (2018). Environmental Policy Integration: Taking Stock of Policy Practice in Different Contexts. Environmental Science \& Policy, 85, 113-115.

Peters, B. G. (2015). Pursuing Horizontal Management: The Politics of Public Sector Coordination. University Press of Kansas.

Pham-Truffert, M., Metz, F., Fischer, M., Rueff, H., \& Messerli, P. (2020). Interactions among Sustainable Development Goals: Knowledge for Identifying Multipliers and Virtuous Cycles. Sustainable Development, 28(5), 1236-1250. https://doi.org/10.1002/sd.2073

Poteete, A. (2012). Levels Scales Linkages and Other "multiples" Affecting Natural Resources. International Journal of the Commons, 6(2), 134-150. https://doi.org/10.18352/ijc.318.

Renou, Y., \& Bolognesi, T. (2019). Governing Urban Water Services in Europe: Towards Sustainable Synchronous Regimes. Journal of Hydrology, 573, 994-1006. https://doi.org/10.1016/j.jhydrol.2018.03.039

Reynard, Emmanuel, Corine Mauch, and Adèle Thorens. 2000. 'Screening Historique Des Régimes Institutionnels de La Ressource En Eau En Suisse Entre 1870 et 2000'. IDHEAP Working Paper 6. Lausanne: IDHEAP.

Roland, G. (2004). Understanding Institutional Change: Fast-Moving and Slow-Moving Institutions. Studies in Comparative International Development, 38(4), 109-131. https://doi.org/10.1007/BF02686330

Schnitter, Niklaus. 1992. Die Geschichte Des Wasserbaus in Der Schweiz. Vol. 2. Olynthus.

Swann, W. L., \& Kim, S. Y. (2018). 'Practical Prescriptions for Governing Fragmented Governments. Policy \& Politics, 46(2), 273-292. https://doi.org/10.1332/030557318X15230058720979

Teisman, G. R., \& Edelenbos, J. (2011). Towards a Perspective of System Synchronization in Water Governance: A Synthesis of Empirical Lessons and Complexity Theories. International Review of Administrative Sciences, 77(1), 101-118. https://doi.org/10.1177/0020852310390121

Thiel, A., Garrick, D. E., \& Blomquist, W. A. (2019). Governing Complexity Analyzing and Applying Polycentricity. Cambridge University Press.

Tosun, J., \& Lang, A. (2017). Policy Integration: Mapping the Different Concepts. Policy Studies, 38(6), 553570. https://doi.org/10.1080/01442872.2017.1339239

Trein, P. (2017). A New Way to Compare Horizontal Connections of Policy Sectors: "Coupling" of Actors, Institutions and Policies. Journal of Comparative Policy Analysis: Research and Practice, 19(5), 419434. https://doi.org/10.1080/13876988.2016.1225342

Trein, P., Biesbroek, R., Bolognesi, T., Cejudo, G. M., Duffy, R., Hustedt, T., \& Meyer, I. (2021). Policy Coordination and Integration: A Research Agenda. Public Administration Review (early View). https://doi.org/ 10.1111/puar.13180

Trein, P., \& Maggetti, M. (2020). Patterns of Policy Integration and Administrative Coordination Reforms: A Comparative Empirical Analysis. Public Administration Review, 80(2), 198-208. https://doi.org/10.1111/ puar. 13117

Trein, P., Meyer, I., \& Maggetti, M. (2018). The Integration and Coordination of Public Policies: A Systematic Comparative Review. Journal of Comparative Policy Analysis: Research and Practice (early View). https://doi.org/10.1080/13876988.2018.1496667

Underdal, A. (1980). Integrated Marine Policy: What? Why? How? Marine Policy, 4(3), 159-169. https://doi. org/10.1016/0308-597X(80)90051-2

Varone, Frédéric, and Stéphane Nahrath. 2014. 'Regulating the Use of Natural Resources: When Policy Instruments Meet Property Rights'. In L'instrumentation de l'action Publique. Controverses, Resistances, Effets, 237-64. Paris: Presses de Sciences Po.

Varone, F., Nahrath, S., Aubin, D., \& Gerber, J.-D. (2013). Functional Regulatory Spaces. Policy Sciences, 46(4), 311-333. https://doi.org/10.1007/s11077-013-9174-1

Varone, F., Reynard, E., Kissling-Näf, I., \& Mauch, C. (2002). Institutional Resource Regimes: The Case of Water Management in Switzerland. Integrated Assessment, 3(1), 78-94. https://doi.org/10.1076/iaij.3.1. 78.7412

Vatn, A. (2005). Institutions and the Environment. Edward Elgar Publishing.

Williamson, O. E. (1985). The Economic Institutions of Capitalism. The Free Press.

Yi, H., Suo, L., Shen, R., Zhang, J., Ramaswami, A., \& Feiock, R. C. (2018). Regional Governance and Institutional Collective Action for Environmental Sustainability. Public Administration Review, 78(4), 556-566. https://doi.org/10.1111/puar.12799 
Zaugg, M. (2006). Philosophiewandel Im Schweizerischen Wasserbau: Zur Vollzugspraxis Des Nachhaltigen Hochwasserschutzes. Geographisches Institut-Abt. Humangeographie/Univ.

Publisher's Note Springer Nature remains neutral with regard to jurisdictional claims in published maps and institutional affiliations. 